\title{
FLORA MEDICINAL GUARANI E KAIOWÁ: CONHECIMENTO TRADICIONAL COMO FORMA DE RESISTÊNCIA
}

SÔNIA PAVÃO ${ }^{1}$

$U F G D, B R A S I L$

http://orcid.org/0000-0003-4745-3712

INAIR GOMES LOPES ${ }^{2}$

UFGD, BRASIL

https://orcid.org/0000-0002-5830-9276

KELLEN NATALICE VILHARVA ${ }^{3}$

UFGD, BRASIL

http://orcid.org/0000-0003-2153-6229

ANASTÁCIO PERALTA ${ }^{4}$

UFGD, BRASIL

https://orcid.org/0000-0001-9457-2568

MARILDO DA SILVA PEDRO 5

UFGD, BRASIL

http://orcid.org/0000-0001-7598-3652

ELIEL BENITES ${ }^{6}$

UFGD, BRASIL

https://orcid.org/0000-0002-0034-4589

LAURA JANE GISLOTI ${ }^{7}$

UFGD, BRASIL

http://orcid.org/0000-0002-3954-0245

\footnotetext{
${ }^{1}$ Mestranda pelo Programa de Pós Graduação em Educação e Territorialidade (PPGET/UFGD). E-mail: soniapavaogk@gmail.com

${ }^{2}$ Mestranda pelo Programa de Pós Graduação em Educação e Territorialidade (PPGET/UFGD). E-mail: inairlopes@gmail.com

${ }^{3}$ Mestra pelo Programa de Pós Graduação em Biologia Geral/Bioprospecção (PPGBG/UFGD). E-mail: kellnatalice@outlook.com

${ }^{4}$ Mestrando pelo Programa de Pós Graduação em Educação e Territorialidade (PPGET/UFGD). E-mail: xirukarai@gmail.com

5 Mestrando pelo Programa de Pós Graduação em Entomologia e Conservação da Biodiversidade (PPGECB/UFGD). E-mail: marildodasilvapedro228@gmail.com

6 Doutorando no Programa de Pós-Graduação em Geografia (PPGG/UFGD). E-mail: elielbenites@ufgd.edu.br

7 Professora do Programa de Pós Graduação em Educação e Territorialidade (PPGET/FAIND) e do Programa de Pós Graduação em Entomologia e Conservação da Biodiversidade (PPGECB/FCBA). E-mail: lauragisloti@gmail.com 
RESUMO: Os povos guarani e kaiowá travam, no centro oeste do Brasil, uma batalha contra o roubo de suas terras tradicionais pelo agronegócio que é imperante na região, fazendo com que a luta em defesa de seus territórios seja marcada por estratégias complexas baseadas na valorização de seus conhecimentos tradicionais. A partir da análise da literatura disponível, realizamos uma leitura critica das evidências encontradas para fornecer um bom cenário dos estudos etnobotânicos sobre esses povos e, assim, confeccionamos uma matriz de dados com informações a respeito das espécies encontradas. Encontramos sete trabalhos sobre plantas medicinais utilizadas por esses povos, com um total de 209 espécies de plantas, incluídas em 175 gêneros e 73 famílias. Concluímos que, apesar da importância desse tema para esses povos, não há grande número de estudos etnobotânicos disponiveis, sendo necessário organizar esforços para preencher lacunas em diferentes áreas do conhecimento e aperfeiçoar a busca por estratégias que possibilitem aos guarani e kaiowá a existência a partir de um modo de vida especifico, que respeita as florestas, as águas, as terras e os demais seres vivos.

PALAVRAS-CHAVE: conhecimento tradicional, etnobotânica, guarani, kaiowá, plantas medicinais.

ABSTRACT: The Guarani and Kaiowá peoples are waging a battle in the central west of Brazil against the theft of their traditional lands by agribusiness that is prevalent in the region, making the struggle in defense of their territories marked by complex strategies based on the valorization of their traditional knowledge. Based on the analysis of the available literature, we performed a critical reading of the available evidence to provide a good scenario of ethnobotanical studies with these peoples, and thus we created a data matrix with information on the species found. We found seven papers on medicinal plants used by these peoples, with a total of 209 species of plants, included in 175 genera and 73 families. We conclude that, despite the importance of this theme for these peoples, there are not a large number of ethnobotanical studies available, and it is necessary to organize efforts to fill gaps in different areas of knowledge and improve the search for strategies that enable Guarani and Kaiowá to exist from a specific way of life that respects forests, waters, lands and other living beings.

KEYWORDS: ethnobotany, guarani, kaiowá, traditional knowledge, medicinal plants. 


\section{Introdução}

Os povos guarani são falantes da língua guarani proveniente do tronco linguístico tupi-guarani cujas diferenças inter-étnicas se evidenciam nas formas linguísticas, costumes, práticas rituais, organizações político-sociais e orientação religiosa; tal como nas formas específicas de cada grupo em interpretar a realidade e interagir de acordo com as situações em sua história. No Brasil, encontram-se subdivididos em três povos: guarani ñandeva, guarani mby'a e guarani kaiowá. Esta pesquisa se refere aos guarani kaiowá e aos guarani ñandeva, segundo maior grupo indígena do $\mathrm{Brasil}^{8}$, inseguramente territorializados no sudoeste do estado de Mato Grosso do Sul e autodenominados guarani e kaiowá.

Os guarani e kaiowá ${ }^{9}$ são conhecidos historicamente como povo da mata ( $k a$ 'agu ygua ou ka'aygua ygua = os da mata, de forma que o próprio nome dos kaiowá surge dessa denominação), pelo fato de escolherem preferencialmente para a localização de suas aldeias áreas de mata. Assim, no decorrer de suas histórias, esses povos ocuparam um amplo espaço, de acordo com a disponibilidade de locais com riquezas naturais consideradas apropriadas. Desta forma, preferiam estabelecer suas aldeias em áreas próximas a cursos de água e à mata. Além disso, o local deveria ser livre de doenças e de ameaças sobrenaturais, sendo desejável que fosse próximo a parentelas aliadas (PEREIRA, 2014; COLMAN e PEREIRA, 2020).

Deste modo, o território tradicionalmente ocupado pelos guarani e kaiowá, no sul do estado do Mato Grosso do Sul, situava-se ao norte até os rios Apa (município de Bela Vista e Dourados) e, ao sul, até a Serra de Maracaju, chegando a uma extensão de leste a oeste de aproximadamente $100 \mathrm{~km}$, em ambos os lados da Serra de Amambai, de modo a abranger uma extensão de terra de aproximadamente $40 \mathrm{mil} \mathrm{km^{2 }}$ entre a fronteira Brasil-Paraguai (MELIÁ et al., 1976). No entanto, as comunidades pertencentes a esse grupo étnico tiveram seus territórios brutalmente reduzidos e atualmente ocupam pequenas áreas situadas em uma faixa de terra de cerca de 150 quilômetros de cada lado da região de fronteira do Brasil com o Paraguai (PEREIRA e MOTA, 2012).

A SESAI - Secretaria Especial de Saúde Indígena - e outros estudiosos da população estimam a população kaiowá atual sendo superior a 50 mil indivíduos (PEREIRA, 2016). Esta população está distribuída em oito reservas, além de quatorze terras indígenas, totalizando 22 áreas indígenas em uma área total de $182,97 \mathrm{~km}^{2}$. No

\footnotetext{
${ }^{8} \mathrm{O}$ Estado brasileiro com maior população indígena é o Amazonas, com 168.680 índios autodeclarados, seguido de Mato Grosso do Sul, com 73.295 indígenas de onze etnias: Guarani Kaiowá, Guarani Ñandeva; Terena; Kinikinau; Kadiwéu; Guató; Chamacoco; Ayoreo; Atikum; Guató; Ofaié e Ofaié-Xavante; o que corresponde a $3 \%$ da população total do Estado e a $9 \%$ da população indígena total no país (CHAMORRO e COMBÈS, 2019).

${ }^{9}$ São várias nomenclaturas encontradas na literatura, como: “Cayuá, Cainguá, Caiowá, Caingá, Caiguá, Kaioá” (GALVÃO, 1996, p. 177). Além de “Kayguá, Kaÿguá, Ka’yguá, Ka’ynguá, Kainguá, Cainguá, Caaguá, Caaingua, Canguá, Cayagua, Cagoa, Cayoa, Caygoa, Cayowa, Caingua, Caa-owa, Cayuás, Cayuáz" (CHAMORRO, 2009, 2014). 
entanto, a maior parte dos guarani e kaiowá vive em condição de Reserva, regime criado no início do século XX, entre os anos de 1915 a 1928, pelo Serviço de Proteção ao Índio (SPI) que tinha como objetivo abrigar os indígenas que estavam sendo expulsos de seus territórios étnicos ancestrais por projetos de colonização. (PEREIRA, 2007; PEREIRA e MOTA, 2012; CAVALCANTE, 2014; MOTA, 2015).

Assim, este processo colonialista devastador tem implicado o extermínio da mata nativa para implantação de monoculturas e pecuária gerando um processo de limitação, tanto geográfica quanto cultural, dos guarani e kaiowá, que veem seu território tradicional dizimado pela cultura do agronegócio imperante na região (BRAND, 2003; SALLES et al., 2016). Diante dessas ações, houve severas mudanças de paisagem, levando a abalos produtivos e fragilizando a segurança alimentar e nutricional das aldeias (PEREIRA, 2007).

Desse modo, os problemas enfrentados pelos guarani e kaiowá estão intimamente relacionados à perda de grande parte do território tradicional, às limitações nas Reservas Indígenas, à degradação ambiental das áreas ocupadas e, por conseguinte, à necessidade de viabilizar a maior parte da economia fora da aldeia, já que no território tradicional a biodiversidade encontra-se drasticamente reduzida (VIETTA, 1998).

Contudo, mesmo diante da brutalidade do extermínio da flora e fauna, tão necessárias à manutenção do modo de vida guarani e kaiowá, desde o final da década de 1990, o número de áreas ocupadas por esses povos vem se ampliando gradativamente. Isto tem ocorrido a partir da reorganização de comunidades que passaram a reivindicar e exigir a demarcação de terras tradicionais expropriadas pela ocupação da agricultura e da pecuária (BENITES, 2014; PEREIRA, 2016). Essa reorganização da luta pela retomada territorial destes povos é pautada a partir de valores arraigados em práticas do bem viver e no manejo respeitoso da flora e fauna e dos ecossistemas locais (PEREIRA, 2014; MONDARDO, 2013, 2020).

Desta maneira, observar, refletir e analisar sobre a forma com que diferentes povos estão lidando e resistindo contra a atual bio/necropolítica da despossessão - que faz com que povos tradicionais sejam massacrados em seus territórios para o estabelecimento do projeto de territorialização corporativa do agronegócio na região centro-oeste do país -, faz-se fundamental para a compreensão de conhecimentos que tenham valor empírico na resistência desses povos contra o avanço da destruição de seus ecossistemas (MOTA e GOETTERT, 2020; MONDARDO, 2020).

As paisagens são frutos de uma história interligada e em comum entre as histórias humanas e naturais (DIEGUES, 2000). Portanto, as transformações das paisagens de populações tradicionais e os processos de reestruturações territoriais, por meio das narrativas dos povos, tornam-se ações políticas e esferas da construção das lutas pelo território. Desse modo, pensar a dimensão da resistência e das lutas territoriais indígenas, correlacionadas às integrações territoriais e ecológicas, nos proporciona refletir sobre diversas outras esferas de resistência ambiental e social. Nessa perspectiva, formas outras de conceber a 
construção de conhecimentos, que se pautem a partir da visão de outros mundos, onde o respeito e a preservação da diversidade da vida, a recusa à racionalidade moderna e o combate direto à devastação ambiental causada pelo colonialismo, nos concedem uma oportunidade rica de refletir sobre os rumos da humanidade, em contraposição ao pensamento e às ações do "povo das mercadorias" e dos "comedores da terra-floresta" (ALBERT, 2002; LATOUR, 2004; KOPENAWA e ALBERT, 2015; KRENAK, 2018).

Assim, no território guarani e kaiowá, de acordo com Benites (2020, p. 20) os elementos que compunham as relações do tekoha (locais onde ocorrem a produção material e cultural desses povos), como a floresta, os rios, a oga pysy (casa de reza) e a roça, são como linhas "condutivas que levam ao passado e às dimensões espirituais e, na volta, trazem a memória viva para atualizar e fundamentar as novas relações necessárias, diante da transformação constante da realidade".

Segundo o autor, o objetivo comum em torno da luta pelo tekoha, é a busca para fortalecer o ñande reko ete (verdadeiro jeito de ser guarani e kaiowá) e recompor os nutrientes da terra. A recuperação da terra é a possibilidade da recuperação da vegetação nativa e, com ela, o microclima local. No decorrer do tempo, esta terra se tornará equilibrada em nível elevado e terá sensibilidade acentuada, permitindo que as trocas e fluxos de energia sejam realidade outra vez (BENITES, 2020, p. 33).

Neste contexto, a Etnobiologia vem se destacando como ciência multi e interdisciplinar, que se debruça sobre as diversas amplitudes das percepções culturais das relações humanos/natureza. Ao relacionar as diferentes formas em que o conhecimento sobre o mundo natural está organizado, a Etnobiologia oferece um tipo de relativismo pelo qual é possível reconhecer outros modelos de relacionamento com a natureza que não necessariamente sejam baseados no racionalismo e no pragmatismo da ciência vigente branca, patriarcal, ocidental e colonialista (SANTOS, 2015). Em paralelo, a Etnobiologia também pode atuar como mediadora entre as diferentes culturas ao assumir seu papel como componente dedicado à compreensão, apoio e respeito mútuo entre os povos (POSEY, 1987).

A vertente da Etnobiologia a ser tratada neste estudo denomina-se Etnobotânica, que se propõe a estudar as interações entre as sociedades humanas e plantas como sistemas dinâmicos, de forma que o cerne dessa ciência seja o estudo das aplicações e dos usos tradicionais e locais dos vegetais pelos humanos, de forma a permitir um melhor entendimento das maneiras pelas quais pessoas em comunidades distintas, pensam, classificam, controlam, manipulam, manejam e utilizam espécies de plantas baseadas em uma dada cultura (ALBUQUERQUE, 2005; ALBUQUERQUE e MEDEIROS, 2012). Consequentemente, a Etnobotânica passou a ser vista como uma ferramenta bastante proveitosa no estudo das mudanças ambientais provocadas por fatores antropogênicos, como o desaparecimento de espécies de plantas, diminuição da diversidade de ecossistemas e introdução de espécies exóticas ou alóctones em determinados ambientes (KING e TEMPESTA, 1994; CUNNINGHAM, 2001; RODRÍGUEZ-SILVA et al., 2020). 
Além disso, atualmente, a Etnobotânica também tem contribuído para que práticas de manejo e ações conservacionistas sejam baseadas na realidade social na qual a comunidade está inserida, visando manter a diversidade biológica e cultural (SCHEFFER, MING, ARAÚJO; 1999; PRADO et al., 2019, SANTOS et al., 2019). Neste sentido, essa pesquisa somou esforços para se unir aos demais trabalhos da área de Etnobiologia focados em uma perspectiva da "Etnobiologia socialmente situada", ou "Etnobiologia da ação", ou ainda da "Etnobiologia engajada", conforme defende o etnobiólogo Flávio Bezerra Barros (TOMCHINSKY et al., 2019).

Assim, apesar de as plantas medicinais serem de grande importância cultural e espiritual na tradição guarani e kaiowá, os estudos até agora realizados sobre o tema nas terras desses povos se limitaram exclusivamente à identificação das plantas de importância medicinal. Análises, comparações e reflexões sobre a temática foram pouco abordadas na literatura atual. Portanto, neste artigo, apresentamos uma visão geral do estado da arte das plantas medicinais usadas tradicionalmente pelos povos guarani e kaiowá, destacando a importância do conhecimento etnobotânico desses povos na luta pela manutenção do modo de vida baseada no bem viver, a qual será possível a partir do processo de retomada de seus territórios e implantação de estratégias de restauração ecológica e conservação da biodiversidade. Com o intuito de aprofundar o diálogo e colocar em prática a confluência de conhecimentos entre o tradicional guarani e kaiowá e o ocidental, apresentamos no desenvolvimento final dos resultados e discussão uma breve passagem a respeito da ótica dos guarani e kaiowá sobre o reino vegetal e as plantas em geral.

\section{Percurso metodológico}

\section{Coleta de dados}

De início é importante refletir sobre a hibridização metodológica e a interculturalidade que perpassa essa pesquisa, já que mescla o olhar de uma pesquisadora não indígena com os olhares guarani e kaiowá de pesquisadoras e pesquisadores indígenas. Nesse sentido, apresentamos inicialmente os dados etnobotânicos oriundos da revisão bibliográfica e, por fim, apresentamos uma breve reflexão sobre a cosmovisão guarani e kaiowá a respeito do mundo das plantas.

Assim, um total de sete estudos (BUENO et al., 2005; REGO et al., 2010; BENITES et al., 2017a; BENITES et al., 2017b; LOPES et al., 2017; JOÃO, 2017; MILLION, 2017) realizados entre 2005 e 2017 nos municípios de Amambai (aldeia Amambai), Caarapó (aldeia Te'yikue), Dourados (aldeia Jaguapiru), Douradina (aldeia Panambi) e Juti (aldeia Taquara), todos do estado do Mato Grosso do Sul, forneceram as informações analisadas (Figura. 1).] 
Figura 1 - Mapa demonstrando a localização dos estudos etnobotânicos dos povos Guarani e Kaiowá examinados neste trabalho.

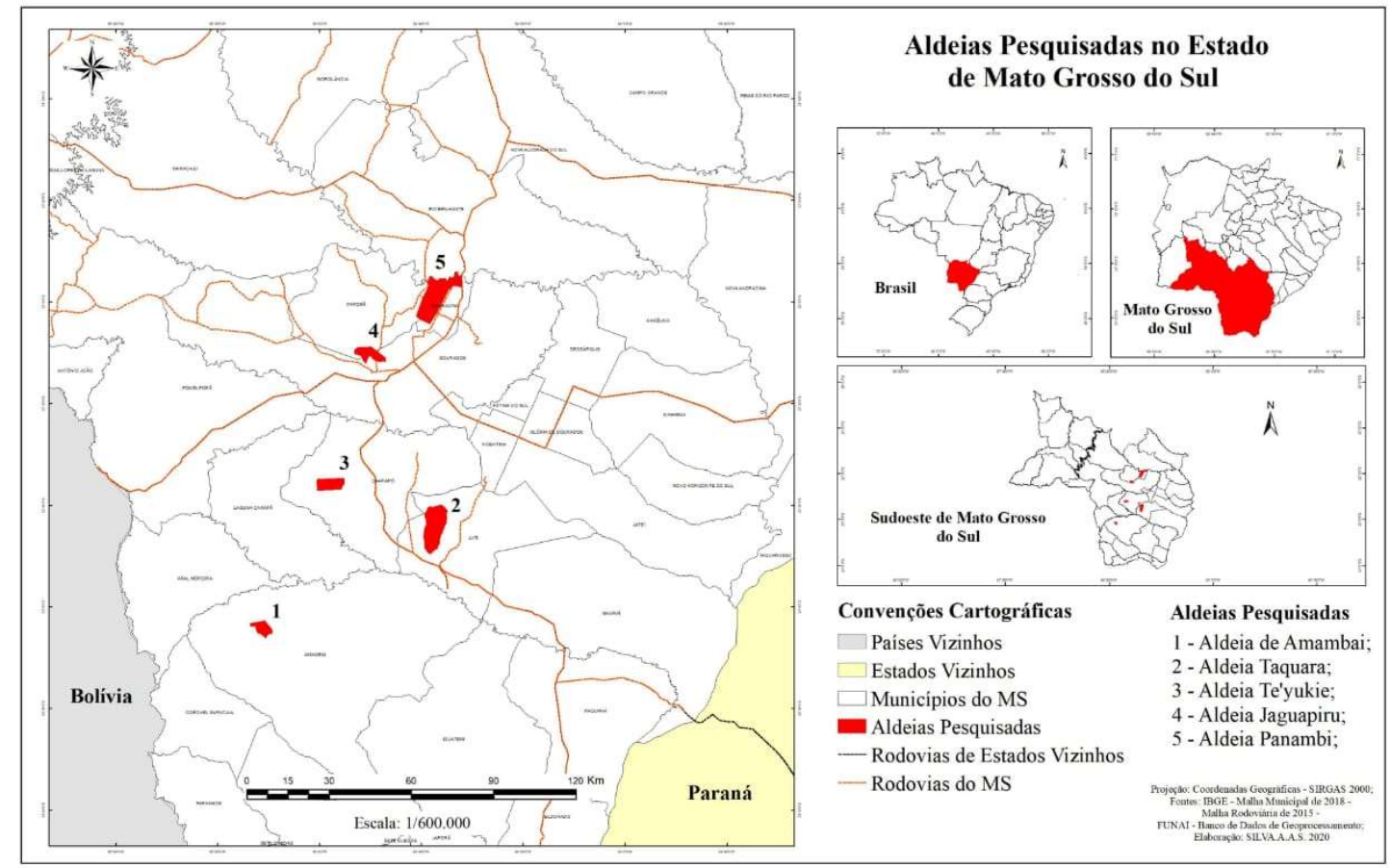

Fonte: Elaboração própria.

Dos sete estudos examinados, seis foram realizados em terras indígenas que já estão homologadas pela Justiça Federal e uma (aldeia Taquara em Juti) consta como terra ainda em processo de disputa judicial. Somente os estudos de texto completo nos quais o material botânico foi cuidadosamente identificado e documentado foram considerados nesta análise.

Nesta pesquisa foram utilizados três bancos de dados (Portal de Periódicos da Capes, Scielo e Google Acadêmico, todos consultados até maio de 2020). Além disso, foram consultadas as referências dos artigos encontrados na pesquisa desses bancos de dados.

A partir das pesquisas analisadas, foram coletadas as seguintes informações: nomes científicos, nomes comuns, nomes êmicos (em guarani e/ou kaiowá), partes utilizadas das plantas e os usos terapêuticos indicados. As espécies de plantas foram classificadas de acordo com o hábito de crescimento como: árvores, arbustos, subarbustos, liana ou herbáceo. Quando os hábitos das plantas não foram especificados no trabalho original, essas informações foram obtidas a partir de consulta ao banco de dados do projeto Flora do Brasil 2020 (http://floradobrasil.jbrj.gov.br/reflora/listaBrasil/ConsultaPublicaUC/Co nsultaPublicaUC.do\#CondicaoTaxonCP) e do Missouri Botanical Garden (MOBOT: http://www.mobot.org), consultados em maio de 2020; ou ainda com a ajuda de especialistas da Universidade Federal da Grande Dourados (UFGD) e da Universidade Estadual do Mato Grosso do Sul (UEMS). 
O termo domínio fitogeográfico no texto e nas tabelas refere-se ao bioma no qual a planta é encontrada. No caso de plantas nativas e plantas exóticas usamos o termo "cultivada".

As análises foram realizadas apenas em plantas identificadas em nível de espécie, mas todas as plantas citadas nos sete estudos consultados estão listadas na Tabela 1. Tivemos o cuidado de empregar apenas os nomes científicos atuais, conforme listado nas bases de dados da Flora do Brasil 2020 e do Missouri Botanical Garden; e para identificar sinônimos usamos a sinonímia entre colchetes na tabela e no texto. Na tabela, tivemos o cuidado de associar os dados com a respectiva citação, de forma que os números sobrescritos correspondem ao número sobrescrito da respectiva referência.

Os usos terapêuticos das plantas medicinais foram ordenados de acordo com os sistemas corporais, seguindo a classificação da organização mundial da saúde (OMS, 2006). Assim, foram definidas doenças do: sistema digestivo; respiratório; aparelho geniturinário; aparelho circulatório; olhos e anexos; ouvidos e processos mastóides; sistema nervoso; infecciosas e parasitárias; pele e tecidos subcutâneos; endócrinas, nutricionais e metabólicas; músculo-esquelético e tecidos conjuntivos; sangue e dos órgãos formadores de sangue; mentais e comportamentais; gravidez, parto e puerpério; neoplasias; lesões, envenenamentos e outras enfermidades por causas externas; e aflições e dores não definidas. No entanto, essa classificação era ocasionalmente subjetiva sendo comum encontrar imprecisões significativas na terminologia médica ou nos usos terapêuticos atribuídos a uma dada planta. Sendo assim, quando uma ampla indicação terapêutica foi encontrada (por exemplo, "inflamações") ou quando sua etiologia não era suficientemente clara, optamos por incluir na categoria "aflições e dores não definidas".

\section{Análise de dados}

As espécies vegetais citadas nos trabalhos analisados foram compiladas e submetidas ao cálculo da Importância Relativa (IR), que considera o número de propriedades farmacológicas e o número de sistemas corporais, associados a uma dada espécie (BENNETT e PRANCE, 2000). Nesse cálculo assume-se que uma planta é mais importante quanto mais versátil se apresenta (maior número de indicações terapêuticas) (ALBUQUERQUE et al., 2010). O valor máximo que uma espécie pode obter é 2,0 . O cálculo é feito de acordo com a seguinte fórmula:

$$
I R=N S C+N I
$$

Onde, IR= importância relativa; NSC= número de sistemas corporais e $\mathrm{NI}=$ número de indicações de uso. O NSC é dado pelo número de sistemas corporais da espécie (NSCS) dividido pelo número de sistemas corporais da espécie mais versátil (NSCSV). Adotou-se como sendo o número de sistemas corporais da espécie mais versátil (NSCSV) a espécie 
que recebeu maior frequência de sistemas corporais citados nos trabalhos consultados. O NI é o número de indicações de uso atribuído à determinada espécie (NIS), dividido pelo número total de indicações de uso da espécie mais versátil (NISV). Entende-se por espécie mais versátil aquela que recebeu maior número de indicações de uso.

O presente estudo empregou esse índice nas análises quantitativas com o intuito de testar a hipótese (usando o teste não-paramétrico de Kruskal-Wallis (SOKAL e RHOLF, 1995), de que a IR pode ser explicada pelo hábito da planta (árvores, arbustos, subarbustos, liana ou herbáceo) ou seu status (nativa ou cultivada). A proporção de espécies nativas vs. cultivadas e os diferentes tipos de hábitos foram comparados pelo teste do qui-quadrado $(\chi 2)$.

\section{Resultados e discussão}

\section{$\underline{\text { Riqueza de plantas medicinais }}$}

Foram registradas um total de 209 espécies de plantas angiospermas incluídas em 175 gêneros e 73 famílias (Tabela 1), além de quatro espécies de samambaias. De todas as catalogadas, 175 são plantas nativas dos domínios fitogeográficos brasileiros, enquanto 30 são cultivadas.

Tabela 1 - Lista de 209 espécies da flora medicinal dos povos guarani e kaiowá citados em sete estudos da região da centro oeste do Brasil.

\begin{tabular}{|c|c|c|c|c|c|c|}
\hline Espécies de Plantas & $\begin{array}{c}\text { Nome } \\
\text { vernacular } \\
\text { (nome em } \\
\text { kaiowá elou } \\
\text { guarani) }\end{array}$ & $\begin{array}{l}\text { Bioma } \\
\text { (hábito) }\end{array}$ & IR & $\begin{array}{c}\text { Informações } \\
\text { de uso }\end{array}$ & $\begin{array}{l}\text { Partes } \\
\text { da } \\
\text { planta }\end{array}$ & Referência \\
\hline
\end{tabular}

\section{ACANTHACEAE}

Justicia brasil

Justicia
Roth

ALISMATACEAE

Echinodorus macrophylus (Kunth) Micheli

$\begin{array}{llllll}\begin{array}{l}\text { junta de cobra } \\ \text { (ysypó poty }\end{array} & \mathrm{M} & 0,2 & \text { cólica menstrual } & \mathrm{Fl}, & \text { Million, } 2017 \\ \text { pytã) } & (\mathrm{sa}) & & & \mathrm{R} & \end{array}$
câncer de boca, câncer de útero, colesterol, celulite, furúnculos, doenças de pele 
Espaço Ameríndio

(sa)

Dysphania ambrosioides

(L.) Mosyakin

\&Clemants ${ }^{1}$

*[Chenopodiumambrosio des L. $]^{2}$

Gomphrena arborescens L.f *[Gomphrena

Gomphrena celosioides Mart.

Gomphrena macrocephala A.St.-Hil.

AMARYLLIDACEAE

Hippeastrum

Herb. sp.

Hippeastrum puniceum (Lam.) Kuntze

lírio

(jarija)
$\mathrm{Cv}$

(sa)

de santa maria ${ }^{23}$

(ka'arẽ)

paratudo

(pyno)

perpétuabrava (sarinha pohã)

paratudo (mbaraka poty)

$\mathrm{Ce}$

(sa)

$\mathrm{Ce}$ (sa) offcinalis Mart.]

$\mathrm{A} / \mathrm{Ca} /$ $\mathrm{Ce} / \mathrm{M}$ (kyse pohã)

ANACARDIACEAE

Myracrodruon

urundeuva Allemão

aroeira

(urunde'y)

(amamba'i kichi pykue)

var. anthriscifoia

(Schrad.) Mickel

ANNONACEAE

Annona coriacea

Mart.

Duguetia furfuracea

(A.St.-Hil.) Saff

APIACEAE

$\begin{array}{ll}\left.\underset{\left(\text { aratikum }^{1},\right.}{\operatorname{araticu}} i^{2}\right) & \mathrm{Ce} \\ \text { araticu }^{2} & (\mathrm{ab})\end{array}$

araticum (aratiku' 'i, yvyra'jatai' $\left.i^{2}\right)$
$\mathrm{A} / \mathrm{Ca} /$

$\mathrm{Ce} / \mathrm{M}$

(av)
$\mathrm{A} / \mathrm{Ca} /$

$\mathrm{Ce} / \mathrm{M} /$

$\mathrm{Pt} / \mathrm{Pa}$

(h)

$\mathrm{A} / \mathrm{Ca} /$

$\mathrm{Ce} / \mathrm{M}$

$/ \mathrm{Pt} / \mathrm{Pa}$

(h)

$\mathrm{Ca} / \mathrm{Ce}$

(av)

$\mathrm{Ce} / \mathrm{M}$

(h)

0,3 parto, pós parto Fo

$\mathrm{C}^{1}, \quad{ }^{1}$ Bueno et al.,

$\mathrm{Fo}^{12} \quad 2005 ;{ }^{2} \mathrm{Rego}$ et al.,

${ }_{34} 2010 ;{ }^{3}$ Lopes et al., 2017; ${ }^{4}$ Benites

et al., 2017b

cicatrizante $^{3}$ digestivo $^{4}$

Fo Benites et al. 2017a

João et al., 2017

tercol $^{1}$,

barriga $^{12}$

coceiras $^{2}$

Benites et al., 2017a
$\mathrm{C}^{12}, \quad{ }^{1}$ Bueno et al., $\mathrm{Fo}^{12}, \quad 2005 ;{ }^{2}$ Benites et $\mathrm{R}^{1} \quad$ al., $2017 \mathrm{a}$ dor de dente ${ }^{1}$ acne $^{2}$

0,3 dor de dente ${ }^{1}$,

Fo $^{1}, \quad{ }^{1}$ Million, 2017; anestésico $^{12} \quad \mathrm{R}^{12} \quad{ }^{2}$ Benites et al., $2017 \mathrm{a}$ 
Espaço Ameríndio

\begin{tabular}{|c|c|c|c|c|c|c|}
\hline $\begin{array}{l}\text { Cyclospermum } \\
\text { leptophyllum } \\
\text { (Pers.) Britton P.Wilson } \\
\text { *[Apium leptophyllum } \\
\text { (Pers.) F. Muell. ex } \\
\text { Benth.] }\end{array}$ & 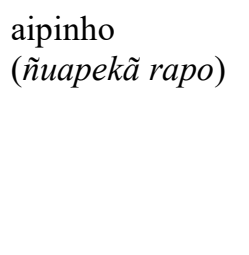 & $\begin{array}{l}\mathrm{CV} \\
(\mathrm{h})\end{array}$ & 0,2 & $\begin{array}{l}\text { inflamação, } \\
\text { corrimento, } \\
\text { coceira dos } \\
\text { órgãos genitais } \\
\text { masculino e } \\
\text { feminino }\end{array}$ & PI & $\begin{array}{l}\text { Benites et } \\
\text { al.,2017a }\end{array}$ \\
\hline $\begin{array}{l}\text { Eryngium pristis } \\
\text { Cham. \& Schltdl }\end{array}$ & $\begin{array}{l}\text { língua de tucano } \\
\text { (karaguata'i) }\end{array}$ & $\begin{array}{l}\mathrm{Ce} / \mathrm{M} \\
\text { (h) }\end{array}$ & 0,2 & dor de cabeça & PI & $\begin{array}{l}\text { Benites et al., } \\
2017 \mathrm{a}\end{array}$ \\
\hline $\begin{array}{l}\text { Foeniculum vulgare } \\
\text { Mill. }\end{array}$ & $\begin{array}{l}\text { rrva doce } \\
\left(k a a^{\prime} a h e^{\prime} \hat{e}\right)\end{array}$ & $\begin{array}{l}\mathrm{CV} \\
\text { (h) }\end{array}$ & 0,3 & $\begin{array}{l}\text { calmante, } \\
\text { relaxante da } \\
\text { pele }\end{array}$ & $\begin{array}{l}\text { Fo, } \\
\text { Fl, } \\
\text { S }\end{array}$ & Lopes et al., 2017 \\
\hline
\end{tabular}

\section{APOCYNACEAE}

Aspidosperma polyneuron Müll.Arg.

peroba

(yvyraro, pytã ${ }^{I}$,

$\mathrm{Ca} / \mathrm{Ce}$ perova $^{2}$ )

(av)

Hemipogon sprucei

E.Fourn.

Mandevilla

pohl(Stadelm.)

A.H.Gentry

Mandevilla widgrenii

C.Ezcurra

(hogueapati'î)

$\mathrm{Ce} / \mathrm{M} /$

$\mathrm{Pt}$

(sa)

Tabernaemontana

catharinensis

pau de leite

(sapirangrỹ)

A.DC.

Tabernaemontana

hystrix Steud.

*[Peschiera fuchsiaefolia

(A. DC.) Miers]

AQUIFOLIACEAE

Ilex paraguariensis

A.St.-Hil.

erva mate

$\left(k a^{\prime} a\right)$

leiteiro

(kurupika' $y^{l}, p y r$

amguỹ $\tilde{y}^{2}$

$\mathrm{Ce} / \mathrm{M}$

$\mathrm{Ce} / \mathrm{M}$

(av)

$\mathrm{A} / \mathrm{Ce}$

(sa)

$\mathrm{Ca} / \mathrm{Ce}$

$/ \mathrm{M} / \mathrm{Pa}$

(sa)

0,9

dor de barriga ${ }^{1}, \quad \mathrm{C}^{23}$ dor de

cabeça ${ }^{1}$,ferida no geral ${ }^{2}$, dor de ouvido $^{2}$, feridas ${ }^{3}$

0,2 inflamação de $\mathrm{R}$

útero

0,4 dor de cabeça,

tensão pré

menstrual,

tontura

0,6 hemorragia, dor $\mathrm{R}$

de cabeça,

tontura

0,6 irritação de

olho,

coceira,picada

de cobra

0,4 picada de

cobra $^{1}$, picada

de mosquito ${ }^{1}$,

dor de ouvido ${ }^{2}$

$\mathrm{Fo}^{1}, \quad{ }^{1}$ Benites et al.,

$\mathrm{C}^{2} \quad 2017 \mathrm{~b} ;{ }^{2}$ João et al., 2017

C Million, 2017

opes et

et al., 2017b

Million, 2017

Million, 2017

Million, 2017
$\mathrm{Ca} / \mathrm{Ce} /$
$\mathrm{M}$

(av)
0,9 coagulante, cicatrizante, estimulante, Parkinson
Fo $\quad$ Million, 2017

Fo, João et al., 2017
Philodendron

bipinnatifdum

Schott cipó-imbé

(begue)
$\mathrm{Ce} / \mathrm{M}$

(1)
0,2 frieira

$\mathrm{R}$ 
Espaço Ameríndio

Schefflera morotoni

(Aubl.) Maguire,

Steyerm. \& Frodin

[*Didymopanax

morototoni

(Aubl.) Maguire]

\section{ARECACEAE}

\section{Butia sp.}

(Becc.) Becc.

Syagrus oleracea

(Mart.) Becc.

\section{ARISTOLOCHIACEAE}

Aristolochia labiata

Willd.

*[Aristolochiabrasiliensi

$s$ Autn]

Aristolochia triangularis Cham. \& Schltd

pindó

$(-)$

$\mathrm{Ce} / \mathrm{M}$

$\mathrm{Pa}$

(av)

guariroba (guavira pytã)

a, $\mathrm{Ce}$ gonorréia

(h)

cipómilombre

(ysypo

$\mathrm{Ca} / \mathrm{Ce} /$

$\mathrm{M}$

milombre ${ }^{1}$,

isypo milõ $\left.{ }^{2}\right)$

(1)

cipómil homens (ysypókatiyngua

(1)

\section{ASTERACEAE}

0,8
verminose $^{1}$, cólica $^{1}$ aperiente $^{2}$, diarreia $^{3}$

dor abdominal ${ }^{1}, \quad \mathrm{PI}^{13}, \quad{ }^{1}$ Bueno et al., febre ${ }^{1}$, vômito ${ }^{1}, \quad \mathrm{C}^{2} \quad 2005$; $^{2}$ Benites et al., 2017a; ${ }^{3}$ João et al., 2017

Million, 2017

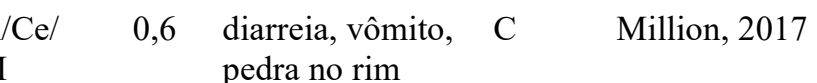

\begin{tabular}{|c|c|c|c|c|}
\hline $\begin{array}{l}\mathrm{Ce} \\
\text { (av) }\end{array}$ & 0,3 & $\begin{array}{l}\text { menstruação } \\
\text { irregular }^{1}, \text { dor } \\
\text { de cabeça }\end{array}$ & $\begin{array}{l}\mathrm{R}, \\
\mathrm{C}^{12} \\
\mathrm{Fo}^{12}\end{array}$ & $\begin{array}{l}{ }^{1} \text { Bueno et al., } \\
\text { 2005; }{ }^{2} \text { Benites et } \\
\text { al., } 2017 \mathrm{~b}\end{array}$ \\
\hline
\end{tabular}

R Rego et al., 2010

Benites et al. 2017a pedra no rim

Achyrocline alata

(Kunth) DC.

(jateika'a)

Achyrocline satureioides(Lam.) DC.

macela

(macela ${ }^{1}$ jateika $\left.\dot{a}^{2}\right)$

$\mathrm{Ca} / \mathrm{Ce} /$

$\mathrm{M} / \mathrm{Pa}$

(h)

$\mathrm{Ce} / \mathrm{M} /$

$\mathrm{Pa}$

(h)
0,7 diarreia,vômito, Fo, Benites et al., verminose, dor Fl 2017a de cabeça

Ageratum conyzoides L.

mentrasto ${ }^{1}$, erva de são joão ${ }^{2}$

\section{$\mathrm{Cv}$} $\left(\right.$ guarapy $\left.^{2}\right)$

(sa)

$\mathrm{A} / \mathrm{M}$

$(-)$

(h)

alecrim do

$\mathrm{Ce} / \mathrm{M} /$

Baccharis dracunculifolia DC.

$\begin{array}{lll}\begin{array}{l}\text { Ambrosia artemisiaefolia } \\ \text { L. }\end{array} & \begin{array}{l}\text { ambrosia } \\ (-)\end{array} & \begin{array}{l}\mathrm{A} / \mathrm{M} \\ \text { (h) }\end{array} \\ \begin{array}{ll}\text { Baccharis } \\ \text { dracunculifolia DC. }\end{array} & \begin{array}{l}\text { alecrim do } \\ \text { campo }\end{array} & \mathrm{Ce} / \mathrm{M} / \\ & (\text { ka'a typy'icha }) & \mathrm{Pa} \\ & (\mathrm{sa})\end{array}$

\section{1,5 digestivo, ${ }^{1}$} reumatismo ${ }^{1}$, diarreia $^{2}$, febre $^{2}$, cólica $^{2}$, gripe $^{2}$, tosse $\mathrm{e}^{2}$, dor no corpo $^{2}$, inflamação de garganta ${ }^{3}$, dor de estômago ${ }^{3}$
0,6 anemia, $\quad \mathrm{R}^{1}, \quad{ }^{1}$ Lopes et al., depurativo ${ }^{1}, \quad \mathrm{Fo}^{2} \quad 2017 ;{ }^{2}$ Benites et diarreia em al., 2017a bebês ${ }^{2}$

$\mathrm{Fo}^{12}, \quad{ }^{1}$ Bueno et al., $\mathrm{Fl}^{23} \quad 2005$; ${ }^{2}$ Benites et al., 2017a; ${ }^{3}$ João et al., 2017
0,2 tranquilizante

Fo

Benites et al.,

1,0 crescimento dos Fo, Lopes et al., 2017 cabelos, dor de $\quad \mathrm{Fl}$
$\mathrm{Pa}$

(sa)

cabeça, dor muscular, pré e pós-parto 
Espaço Ameríndio

\begin{tabular}{|c|c|c|c|c|c|c|}
\hline $\begin{array}{l}\text { Baccharis crispa } \\
\text { Spreng. } \\
\text { *[Baccharis trimera } \\
\text { (Less.) DC. }]\end{array}$ & $\begin{array}{l}\text { carqueja } \\
\left(\text { kacare } \text { ' }^{\prime} a^{1},\right. \\
\left.\text { jakaré ruguai }{ }^{2}\right)\end{array}$ & $\begin{array}{l}\mathrm{Ce} / \mathrm{M} / \\
\mathrm{Pa} \\
(\mathrm{sa})\end{array}$ & 1,2 & $\begin{array}{l}\text { cólica }^{1}, \text { anemia }^{1} \text {, } \\
\text { coceira }^{2}, \text { dor de } \\
\text { estômago }^{2}, \\
\text { DSTs }^{2}, \text { abortiva }^{2}\end{array}$ & $\begin{array}{l}\mathrm{Fr}^{1} \\
\mathrm{Fo}^{2}\end{array}$ & $\begin{array}{l}{ }^{1} \text { Bueno et al., } \\
\text { 2005; }{ }^{2} \text { Lopes et } \\
\text { al., } 2017\end{array}$ \\
\hline $\begin{array}{l}\text { Bidens pilosa } \\
\text { L. }\end{array}$ & $\begin{array}{l}\text { picão } \\
\text { (tapekwecarapix } \\
\text { o) }\end{array}$ & $\begin{array}{l}\mathrm{cV} \\
(\mathrm{h})\end{array}$ & 0,2 & DST & Fo & Million, 2017 \\
\hline $\begin{array}{l}\text { Chaptalia integerrima } \\
\text { (Vell.) Burkart }\end{array}$ & $\begin{array}{l}\text { dente de leão } \\
\text { (ypotyvevea) }\end{array}$ & $\begin{array}{l}\mathrm{Ca} / \mathrm{Ce} / \\
\mathrm{M} \\
(\mathrm{h})\end{array}$ & 0,8 & $\begin{array}{l}\text { dorde dente, } \\
\text { hemorragia, } \\
\text { câncer }\end{array}$ & Fo & Million, 2017 \\
\hline $\begin{array}{l}\text { Chaptalia nutans (L.) } \\
\text { Pol. }\end{array}$ & $\begin{array}{l}\text { língua de vaca } \\
\text { (pohã roỹsa) }\end{array}$ & $\begin{array}{l}\mathrm{A} / \mathrm{Ca} / \mathrm{C} \\
\mathrm{e} / \\
\mathrm{M} \\
\text { (h) }\end{array}$ & 0,3 & $\begin{array}{l}\text { dor nas juntas, } \\
\text { cansaço }\end{array}$ & Fo & $\begin{array}{l}\text { Benites et al., } \\
2017 \mathrm{a}\end{array}$ \\
\hline $\begin{array}{l}\text { Conyza bonariensis (L.) } \\
\text { Conquist }\end{array}$ & $\begin{array}{l}\text { avoadeira } \\
\text { (karumbe mba) }\end{array}$ & $\begin{array}{l}\mathrm{A} / \mathrm{Ca} / \\
\mathrm{Ce} / \mathrm{M} / \\
\mathrm{Pa} / \mathrm{Pt} \\
\text { (sa) }\end{array}$ & 0,2 & câncer & PI & Million, 2017 \\
\hline $\begin{array}{l}\text { Conyza canadenses } \\
\text { (L.)Cronquist }\end{array}$ & $\begin{array}{l}\text { voadeira, buva } \\
(-)\end{array}$ & $\begin{array}{l}\mathrm{A} / \mathrm{Ca} / \\
\mathrm{Ce} / \mathrm{M} / \\
\mathrm{Pa} / \mathrm{Pt} \\
\text { (sa) }\end{array}$ & 0,8 & $\begin{array}{l}\text { depurativo, } \\
\text { leucemia, } \\
\text { tabagismo }\end{array}$ & Fo & $\begin{array}{l}\text { Benites et al., } \\
2017 \mathrm{a}\end{array}$ \\
\hline $\begin{array}{l}\text { Gamochaeta falcata } \\
\text { (Lam.) Cabrera }\end{array}$ & $\begin{array}{l}\text { erva do pombo } \\
(\text { jarutika'a) }\end{array}$ & $\begin{array}{l}\mathrm{M} / \mathrm{Pa} \\
\text { (h) }\end{array}$ & 0,4 & $\begin{array}{l}\text { inflamação do } \\
\text { útero, cólica, } \\
\text { menstruação } \\
\text { irregular }\end{array}$ & Fo & Million, 2017 \\
\hline Melampodium L.sp. & (ivyraro) & $\begin{array}{l}\mathrm{A} / \mathrm{Ce} / \\
\mathrm{M} \\
(\mathrm{ab})\end{array}$ & 0,2 & diarreia & Fo & $\begin{array}{l}\text { Benites et al., } \\
2017 \mathrm{a}\end{array}$ \\
\hline $\begin{array}{l}\text { Mikania glomerata } \\
\text { Spreng. }\end{array}$ & $\begin{array}{l}\text { guaco } \\
\text { (ysypo katĩ) }\end{array}$ & $\begin{array}{l}\mathrm{Ce} / \mathrm{M} \\
\text { (1) }\end{array}$ & 0,2 & DSTs & PI & Lopes et al., 2017 \\
\hline $\begin{array}{l}\text { Moquinia racemosa } \\
\text { (Spreng.) } \\
\text { DC.*[Gochnatia barrosii } \\
\text { Cabrera }]\end{array}$ & $\begin{array}{l}\text { borragem do } \\
\text { campo } \\
(-)\end{array}$ & $\begin{array}{l}\mathrm{Ce} / \mathrm{M} \\
(\mathrm{ab})\end{array}$ & 0,2 & $\begin{array}{l}\text { infecção } \\
\text { respiratória }\end{array}$ & $\begin{array}{l}\text { Fo, } \\
\text { S }\end{array}$ & $\begin{array}{l}\text { Benites et al., } \\
2017 \mathrm{a}\end{array}$ \\
\hline $\begin{array}{l}\text { Moquiniastrum } \\
\text { polymorphum (Less.) } \\
\text { G.Sancho } *[\text { Gochnatia } \\
\text { polymorpha } \text { Herb. Berol } \\
\text { ex DC. }\end{array}$ & 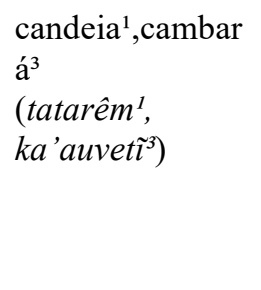 & $\begin{array}{l}\mathrm{Ce} / \mathrm{M} \\
(\mathrm{av})\end{array}$ & 1,4 & $\begin{array}{l}\text { dor de } \\
\text { garganta }^{12}, \\
\text { tosse }^{2}, \text { gripe }^{2} \\
\text { pressão alta }^{2}, \\
\text { febre }^{2}, \\
\text { sarampo }^{2} \text {,hemor } \\
\text { ragia }^{3}, \text { resfriado }^{4}\end{array}$ & $\begin{array}{l}\mathrm{C}^{1} \\
\mathrm{Fo}^{234}\end{array}$ & $\begin{array}{l}{ }^{1} \text { Bueno et al., } \\
\text { 2005; }{ }^{2} \text { Rego et al., } \\
\text { 2010; }{ }^{3} \text { Milllion, } \\
\text { 2017; }{ }^{4} \text { Benites et } \\
\text { al., } 2017 \text { a }\end{array}$ \\
\hline $\begin{array}{l}\text { Porophyllum ruderale } \\
\text { (Jacq.)Cass. }\end{array}$ & $\begin{array}{l}\text { arnica-do-mato }^{1}, \\
\text { picão-branco } \\
(y r y v u \\
\left.k a^{\prime} a^{1}, \text { arnica }^{2}\right)\end{array}$ & $\begin{array}{l}\mathrm{Ca} / \mathrm{Ce} / \\
\mathrm{MA} / \mathrm{Pa} / \\
\mathrm{Pt} \\
\text { (h) }\end{array}$ & 2,0 & $\begin{array}{l}\text { dor de cabeça }{ }^{12}, \\
\text { enxaqueca }^{1}, \\
\text { coceira de } \\
\text { pele }^{12}, \text { DSTs }^{12}, \\
\text { dor nas }\end{array}$ & $\begin{array}{l}\mathrm{PI}^{1} \\
\mathrm{Fo}^{2}\end{array}$ & $\begin{array}{l}{ }^{1} \text { Lopes et al., } \\
\text { 2017; }{ }^{2} \text { Benites et } \\
\text { al., } 2017 \mathrm{a}\end{array}$ \\
\hline
\end{tabular}


Espaço Ameríndio

\begin{tabular}{|c|c|c|c|c|c|c|}
\hline $\begin{array}{l}\text { Pterocaulon lanatum } \\
\text { Kuntze }\end{array}$ & $\begin{array}{l}\text { branqueja }^{1}, \\
\text { verbasco }^{2} \\
\left(\text { kypohä }^{I}\right) \\
\text { ivitymoroti } \\
\text { ivity }^{2}\end{array}$ & $\begin{array}{l}\mathrm{Ce} / \mathrm{M} / \\
\mathrm{Pa} \\
\text { (h) }\end{array}$ & 0,3 & $\begin{array}{l}\text { escabiose }^{1} \text {, } \\
\text { feridas }^{1} \text {, dor nos } \\
\text { olhos }^{2}\end{array}$ & $\mathrm{Fo}^{12}$ & $\begin{array}{l}{ }^{1} \text { Milllion, 2017; } \\
{ }^{2} \text { Benites et al., } \\
2017 \mathrm{a}\end{array}$ \\
\hline $\begin{array}{l}\text { Solidago chilensis } \\
\text { Meyen *[Solidago } \\
\text { microglossa DC. }]\end{array}$ & $\begin{array}{l}\text { arnica do campo } \\
\left(\text { taji pita }^{\prime} i\right)\end{array}$ & $\begin{array}{l}\mathrm{Ca} / \mathrm{Ce} / \\
\mathrm{M} / \mathrm{Pa} \\
(\mathrm{sa})\end{array}$ & 0,2 & doenças renais & $\mathrm{R}$ & Bueno et al., 2005 \\
\hline $\begin{array}{l}\text { Tithonia diversifolia } \\
\text { (Hemsl.) A. Gray }\end{array}$ & $\begin{array}{l}\text { margaridão } \\
\text { (pyngcipỹ) }\end{array}$ & $\begin{array}{l}\mathrm{cV} \\
(\mathrm{sa})\end{array}$ & 0,2 & dor de estômago & Fo & João et al., 2017 \\
\hline $\begin{array}{l}\text { Trixis antimenorrhoea } \\
\text { (Schrank) Kuntze }\end{array}$ & $\begin{array}{l}\text { erva do burro } \\
\text { (miririka ka'a) }\end{array}$ & $\begin{array}{l}\mathrm{Ce} / \mathrm{M} \\
\text { (sa) }\end{array}$ & 0,3 & $\begin{array}{l}\text { Inflamação } \\
\text { urinária, DSTs }\end{array}$ & $\begin{array}{l}\text { Fo, } \\
\text { R }\end{array}$ & Milllion, 2017 \\
\hline Xanthium spinosum L. & $\begin{array}{l}\text { espinho de } \\
\text { carneiro } \\
(-)\end{array}$ & $\begin{array}{l}\mathrm{cv} \\
(\mathrm{h})\end{array}$ & 0,2 & $\begin{array}{l}\text { infecções das } \\
\text { vias urinárias }\end{array}$ & PI & $\begin{array}{l}\text { Benites et al., } \\
2017 \mathrm{a}\end{array}$ \\
\hline \multicolumn{7}{|l|}{ BIGNONIACEAE } \\
\hline Bignonia binata Thunb. & $\begin{array}{l}\text { cipó vaqueiro } \\
(\text { ysypó } h \tilde{u})\end{array}$ & $\begin{array}{l}\mathrm{A} / \mathrm{Ca} / \\
\mathrm{Ce} / \mathrm{M} \\
\text { (1) }\end{array}$ & 0,2 & diabetes & $\mathrm{C}$ & Milllion, 2017 \\
\hline $\begin{array}{l}\text { Cybistax antisyphilitica } \\
\text { (Mart.) Mart. }\end{array}$ & $\begin{array}{l}\text { caroba de folha } \\
\text { verde } \\
\text { (tovape syi) }\end{array}$ & $\begin{array}{l}\mathrm{A} / \mathrm{Ca} / \\
\mathrm{Ce} / \mathrm{M} / \\
\mathrm{Pt} \\
\text { (av) }\end{array}$ & 0,2 & cólica menstrual & $\begin{array}{l}\mathrm{C} \\
\mathrm{R}\end{array}$ & Milllion, 2017 \\
\hline $\begin{array}{l}\text { Dolichandra unguis-cati } \\
\text { (L.)L.G.Lohmann }\end{array}$ & $\begin{array}{l}\text { unha de gato } \\
\text { (mbaraka-ja } \\
\text { pyapê) }\end{array}$ & $\begin{array}{l}\mathrm{A} / \mathrm{Ca} / \\
\mathrm{Ce} / \mathrm{M} \\
/ \mathrm{Pa} / \mathrm{Pt} \\
\text { (1) }\end{array}$ & 0,3 & $\begin{array}{l}\text { cicatrizante, } \\
\text { limpa o útero }\end{array}$ & $\begin{array}{l}\text { Fr, } \\
\text { Fo }\end{array}$ & Milllion, 2017 \\
\hline $\begin{array}{l}\text { Fridericia florida (DC.) } \\
\text { L.G.Lohmann }\end{array}$ & $\begin{array}{l}\text { cipó-neve } \\
\text { (gwiri puña) }\end{array}$ & $\begin{array}{l}\mathrm{A} / \mathrm{M} / \\
\mathrm{Ce} \\
(1)\end{array}$ & 0,2 & pneumonia & $\mathrm{R}$ & Million, 2017 \\
\hline $\begin{array}{l}\text { Handroanthus } \\
\text { impetiginosus(Mart. ex } \\
\text { DC.) Mattos] *[ } \\
\text { Tabebuia avellanedae } \\
\text { Lorentz ex Griseb.] }\end{array}$ & $\begin{array}{l}\text { ipê-roxo } \\
\text { (tajy) }\end{array}$ & $\begin{array}{l}\mathrm{M} / \mathrm{Ce} \\
\text { (av) }\end{array}$ & 0,3 & $\begin{array}{l}\text { tuberculose, } \\
\text { febre }\end{array}$ & $\mathrm{C}$ & Bueno et al., 2005 \\
\hline $\begin{array}{l}\text { Jacaranda ulei Bureau \& } \\
\text { K.Schum. }\end{array}$ & $\begin{array}{l}\text { carobinha } \\
\text { (hogue } \\
\text { sarambia) }\end{array}$ & $\begin{array}{l}\mathrm{Ce} \\
(\mathrm{av})\end{array}$ & 0,2 & cólica menstrual & $\mathrm{R}$ & Million, 2017 \\
\hline $\begin{array}{l}\text { Mansoa difficilis } \\
\text { (Cham.) Bureau } \\
\text { \&K.Schum. }\end{array}$ & $\begin{array}{l}\text { cipó alho } \\
\text { (ysypó ryakuã) }\end{array}$ & $\begin{array}{l}\mathrm{A} / \mathrm{M} / \\
\mathrm{Ce} \\
(1)\end{array}$ & 0,9 & $\begin{array}{l}\text { tontura, } \\
\text { bronquite, }\end{array}$ & $\begin{array}{l}\mathrm{C} \\
\mathrm{R}\end{array}$ & Million, 2017 \\
\hline
\end{tabular}

articulações ${ }^{1}$,

dor nos olhos ${ }^{2}$,

dorno

estômago ${ }^{1}$,

reumatismo ${ }^{2}$,

circulação ${ }^{2}$,

dor $^{2}$, machucadu

$\mathrm{ra}^{2}$ 
Espaço Ameríndio

BIXACEAE

\begin{tabular}{|c|c|c|c|c|c|c|}
\hline Bixa orellanaL. & $\begin{array}{l}\text { urucum } \\
\left(u r u k u^{1}, y r u c \breve{u}^{2}\right)\end{array}$ & $\begin{array}{l}\mathrm{A} / \mathrm{Ce} / \\
\mathrm{M} \\
(\mathrm{ab})\end{array}$ & 1,00 & $\begin{array}{l}\text { extração de } \\
\text { dente }^{1}, \\
\text { diabetes }^{2}, \\
\text { queimaduras de } \\
\text { sol }^{3}, \text { manchas da } \\
\text { pele }^{3}, \text { sarna }^{4}\end{array}$ & $\begin{array}{l}\mathrm{R}^{12} \\
\mathrm{C}^{1}, \mathrm{Fo} \\
, \mathrm{Fr}^{3} \\
\mathrm{~S}^{4}\end{array}$ & $\begin{array}{l}{ }^{1} \text { Bueno et al., } \\
\text { 2005; }{ }^{2} \text { Million, } \\
\text { 2017; }{ }^{3} \text { Lopes et } \\
\text { al., } 2017 ;{ }^{4} \text { João et } \\
\text { al., } 2017\end{array}$ \\
\hline $\begin{array}{l}\text { Cochlospermum regium } \\
\text { (Mart. ex Schrank)Pilg. }\end{array}$ & $\begin{array}{l}\text { algodãozinho } \\
\text { (nhara kati'y } \\
\text { rã) }\end{array}$ & $\begin{array}{l}\mathrm{A} / \mathrm{Ca} / \\
\mathrm{Ce} / \mathrm{Pt} \\
(\mathrm{ab})\end{array}$ & 0,6 & $\begin{array}{l}\text { pedra na } \\
\text { vesícula, dor de } \\
\text { estômago, dor } \\
\text { de rim }\end{array}$ & $\begin{array}{l}\text { Fo, } \\
\text { R }\end{array}$ & Million, 2017 \\
\hline
\end{tabular}

BOMBACACEAE

Eriotheca candolleana

catuaba

(K.Schum.)A.Robyns

(yvá porû)

$\mathrm{Ce} / \mathrm{M}$

0,3 reumatismo,

$\mathrm{R}$

Bueno et al., 2005

BORAGINACEAE

Cordia americana (L.)

guajuvira

Gottshling \& J.E.Mill. *[ (guajayvi)

M

(av)

0,2 controle de

pressão
C Benites et al., 2017b

\section{L.]}

\section{BROMELIACEAE}

Ananas ananassoides (Baker) L.B.Sm.

bromélia ${ }^{1}$,

$\mathrm{A} / \mathrm{Ca} /$ ananas-do-mato ${ }^{2}$

(karaguata

$\mathrm{Ce} / \mathrm{M}$

pytã ${ }^{I}$, karaguata

(h)

$\left.y^{2}\right)$

Bromelia antiacantha

bromélia $^{1}$,

caraguatá ${ }^{2}$

(karaguata

ju, karaguata $^{2}$ )

$\mathrm{M} / \mathrm{Pa}$

(h)

1,2 dor de ouvido, gripe, dor de

$\mathrm{Fo}^{1}, \quad{ }^{1}$ Million, 2017; garganta $^{1}$, problemas respiratórios, anemia $^{2}$, vermicida $^{3}$

$\mathrm{Fr}^{12} \quad{ }^{2}$ Benites et al., 2017a; ${ }^{3}$ João et al., 2017

amescla $^{1}$, breu ${ }^{2} \quad \mathrm{~A} / \mathrm{Ca}$ (ysy)

1,1 dor de barriga ${ }^{12}$,

$\mathrm{C}^{12}, \mathrm{~S}$ dor nas juntas ${ }^{1}$, grip $^{2}$, dor no corpo $^{2}$, inflamação ${ }^{2}$

${ }^{1}$ Rego et al., 2010; ${ }^{2}$ Benites et al., 2017b

\section{CACTACEAE}

Nopalea cochenillifera (L.) Salm-Dyck[Opuntia cochenillifera (L.) Mill.]
cacto,mandacar $\mathrm{u}$ (tuna)
$\mathrm{cv}$
(ab)
0,8 feridas ${ }^{1}$, inflamação na vesícula $^{1}$, auxilia parto ${ }^{2}$

\section{CARYOCARACEAE}


Espaço Ameríndio

\begin{tabular}{|c|c|c|c|c|c|c|}
\hline $\begin{array}{l}\text { Caryocar brasiliense } \\
\text { Cambess. }\end{array}$ & $\begin{array}{l}\text { pequi } \\
(\text { peky) }\end{array}$ & $\begin{array}{l}\mathrm{A} / \mathrm{Ca} / \\
\mathrm{Ce} / \mathrm{M} \\
(\mathrm{av})\end{array}$ & 0,2 & dor de barriga & Fr & Million, 2017 \\
\hline \multicolumn{7}{|l|}{ CELASTRACEAE } \\
\hline Hippocratea volubilis $\mathrm{L}$. & $\begin{array}{l}\text { cipó-preto } \\
\text { (ka hogue ne) }\end{array}$ & $\begin{array}{l}\mathrm{A} / \mathrm{Ca} / \\
\mathrm{Ce} / \mathrm{M} / \\
\mathrm{Pt} \\
(\mathrm{l})\end{array}$ & 0,3 & gripe, tontura & Fo & Million, 2017 \\
\hline Platonia insignis Mart. & $\begin{array}{l}\text { bacuri } \\
(-)\end{array}$ & $\begin{array}{l}\mathrm{A} / \mathrm{Ce} \\
\text { (av) }\end{array}$ & 0,2 & diabetes & $\mathrm{C}$ & Rego et al., 2010 \\
\hline $\begin{array}{l}\text { Maytenus ilicifolia } \\
\text { Mart.ex Reiss }\end{array}$ & $\begin{array}{l}\text { cancorosa, } \\
\text { espinheira santa } \\
\text { (kangorosa }^{12} \text {, } \\
\left.\text { jyreỹjari }^{34}\right)\end{array}$ & $\begin{array}{l}\mathrm{Ce} / \mathrm{M} / \\
\mathrm{Pa} \\
(\mathrm{ab})\end{array}$ & 2,0 & $\begin{array}{l}\text { dor de barriga }{ }^{12} \text {, } \\
\text { cicatrização de } \\
\text { feridas }^{1} \text {, dor de } \\
\text { cabeça }^{2}, \\
\text { vômito }^{2} \text {, dor de } \\
\text { coluna }^{2} \text {, cólica } \\
\text { dor de } \\
\text { estômago } \\
\text { sinusite }^{3} \text {, } \\
\text { câimbras }^{3} \text {,diarre } \\
\text { ia }^{34}\end{array}$ & $\begin{array}{l}\mathrm{PI}^{1} \\
\mathrm{R}^{234} \\
\mathrm{C}^{3}\end{array}$ & $\begin{array}{l}{ }^{1} \text { Bueno et al., } \\
\text { 2005; }{ }^{2} \text { Million, } \\
\text { 2017; }{ }^{3} \text { Benites et } \\
\text { al., } 2017 \mathrm{a} ;{ }^{4} \text { João } \\
\text { et al., } 2017\end{array}$ \\
\hline $\begin{array}{l}\text { Maytenus floribunda } \\
\text { Steyerm. * [Maytenus } \\
\text { pittieriana Steyerm.] }\end{array}$ & $\overline{-}($ poty juva $)$ & $\begin{array}{l}\mathrm{Ce} / \mathrm{M} \\
(\mathrm{ab})\end{array}$ & 0,6 & $\begin{array}{l}\text { dor de barriga, } \\
\text { diarreia, rim }\end{array}$ & $\begin{array}{l}\text { Fo, } \\
\text { R }\end{array}$ & Million, 2017 \\
\hline \multicolumn{7}{|l|}{ CLUSIACEAE } \\
\hline $\begin{array}{l}\text { Garcinia gardneriana } \\
\text { (Planch. \&Triana Zappi. }\end{array}$ & $\begin{array}{l}\text { bacupari } \\
\text { (pakury) }\end{array}$ & $\begin{array}{l}\mathrm{A} / \mathrm{Ca} / \\
\mathrm{Ce} / \mathrm{M} \\
(\mathrm{av})\end{array}$ & 0,3 & $\begin{array}{l}\text { feridas na boca }{ }^{1} \text {, } \\
\text { feridas em } \\
\text { geral }^{2}\end{array}$ & $\mathrm{C}$ & $\begin{array}{l}{ }^{1} \text { Benites et al., } \\
2017 \mathrm{a} ;{ }^{2} \text { Benites et } \\
\text { al., } 2017 \mathrm{~b}\end{array}$ \\
\hline
\end{tabular}

\section{COSTACEAE}

Costus spicatus (Jacq.) cana do brejo $\quad$ A/M

Sw.

(kanã brasa)

(h)
1,1 DSTs, ${ }^{1}$ infecção $\quad \mathrm{R}^{12} \quad{ }^{1}$ Benites et al., de urina ${ }^{1}$, 2017a; ${ }^{2}$ João et cicatrizante $^{1}$ al., 2017 fortalecer os nervos $^{2}$, problema renal $^{2}$

\section{CUCURBITACEAE}

Citrullus lanatus

(Thunb.) Matsum. \&

Nakai $*[$ Citrullus

vulgarisSchrad.]

Momordica charantia L.

melão de

sãocaetano

(ka'i tupa)

\section{CYPERACEAE}

Cyperus sp. melancia

$(-)$

(1)
0,3 coceira, sarna

Fo

Lopes et al., 2017

0,3 cólica, vômito

S

Bueno et al., 2005

(1)
Benites et al., $2017^{\mathrm{a}}$ 
Espaço Ameríndio

\begin{tabular}{|c|c|c|c|c|c|}
\hline Scleria hirtella Sw. & $\begin{array}{l}\text { junco de cobra } \\
\text { (pikatim) }\end{array}$ & $\begin{array}{l}\mathrm{A} / \mathrm{Ca} / \\
\mathrm{Ce} / \mathrm{M} / \\
\mathrm{Pa} / \mathrm{Pt}\end{array}$ & 0,2 & lombriga & Million, 2017 \\
\hline
\end{tabular}

ERIOCAULACEAE

(h)

Syngonanthus Cscens

(Poir.)Ruhland

mosquito

amarelo

(karaguatai)

$\mathrm{A} / \mathrm{Ce} /$

$\mathrm{M}$

(h)

0,6

fortifica o útero, $\quad \mathrm{R}$

cólica

menstrual, dor de ouvido

\section{ERYTHROXYLACEAE}

Erythroxylum
vacciniifolium Mart.

EUPHORBIACEAE

Croton L.sp.

Croton floribundus

Spreng.

Croton urucurana Bail catuaba

(katu ara)

$\mathrm{Ca} / \mathrm{Ce}$

$\mathrm{M}$

(ab)

\section{$\mathrm{Ca} / \mathrm{Ce} /$}

(eirusu ka'a)

capixingui

(yvyravevýi ${ }^{1}$, tatare $\tilde{e}^{2}$, yvyra parãra $\tilde{a}^{3}$ )

sangra
d'água $^{1}$,árvore
vermelha $^{2}$
$\left(u r u c u r \tilde{a}^{I}\right.$, yviro
pyto $\left.^{2}\right)$

$\mathrm{A} / \mathrm{Ce} /$ $\mathrm{M}$ (av)

(av)

$\mathrm{Ca} / \mathrm{Ce} /$ $\mathrm{M}$

(av)

0,2 depressão pós
parto

1,0 dor de garganta $^{13}$, sarampo $^{1}$, dor de barriga $^{1}$, dor no útero $^{2}$

1,7 cicatrizante ${ }^{1}$, adstringente $^{1}$, antisséptico $^{1}$, dor de barriga ${ }^{1}$, feridas na boca $^{1234}$, dores nas pernas ${ }^{2}$, feridas na pele ${ }^{2}$, inflamação de garganta $^{4}$, diarreia $^{4}$
C Benites et al., $2017^{\mathrm{a}}$

Fo Benites et al., $2017^{\mathrm{a}}$

$\mathrm{C}^{13}, \quad{ }^{1}$ Rego et al., 2010; $\mathrm{R}^{12} \quad{ }^{2}$ Million, 2017; ${ }^{3}$ Benites et al., $2017^{\mathrm{a}}$

$\mathrm{C}^{123}, \quad{ }^{1}$ Lopes et al., $\mathrm{Sv}^{134} \quad 2017 ;{ }^{2}$ Benites et al., 2017a; ${ }^{3}$ Benites et al., 2017b; ${ }^{4}$ João et al., 2017

\section{FABACEAE}

Albizia niopoides

(Spruce ex Benth.)

Burkart*[Albizia

hasslerri (Chodat) Burr.]

Albizia polycephala
(Benth.) Killip ex Record

Amburana cearenses
(Allemão) A.C.Sm.

Anadenanthera

colubrina(Vell.) Brenan farinha seca

(Ko)

$\mathrm{A} / \mathrm{Ce} /$

$\mathrm{M}$

(ab)

albízia

(kurupa'yrã)

$\mathrm{Ca} / \mathrm{Ce} / \quad 0,2$ dor nos olhos

$\mathrm{M}$

(av)

moarama,

angelin

(yvyraju)

$\mathrm{Ca} / \mathrm{Ce} /$
$\mathrm{M}$

(av)

dor no

estômago, má

circulação,

afinar o sangue

angico-branco ${ }^{1}$

$\left(\right.$ timbo' $\left.y^{2}\right)$
$\mathrm{Ce} / \mathrm{M}$ coceira $^{1}$, tumor $^{1}, \quad \mathrm{C}^{2}$ sarna, ${ }^{2}$ ressaca ${ }^{2}$, ferida $^{2}$

\section{Benites et al.,} $2017 b$

Rego et al., 2010

C João et al., 2017

${ }^{1}$ Rego et al., 2010;

${ }^{2}$ Million, 2017 
Espaço Ameríndio

\begin{tabular}{|c|c|c|c|c|c|c|}
\hline $\begin{array}{l}\text { Anadenanthera } \\
\text { peregrina }(\text { Benth.) } \\
\text { Altschul* }[\text { Anadenanther } \\
\text { a falcata }(\text { Benth. })]\end{array}$ & $\begin{array}{l}\text { angico }^{1} \text {, angico } \\
\text { preto }^{2} \\
\left(\text { kurupa }^{2}\right. \\
\text { yguasu }\end{array}$ & $\begin{array}{l}\mathrm{Ca} / \mathrm{Ce} / \\
\mathrm{M} \\
(\mathrm{ab})\end{array}$ & 0,8 & 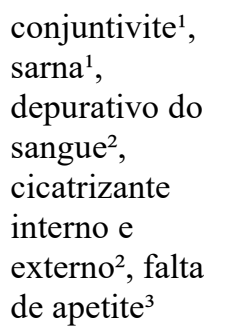 & $\mathrm{C}^{123}$ & $\begin{array}{l}{ }^{1} \text { Bueno et al., } \\
\text { 2005; }{ }^{2} \text { Benites et } \\
\text { al., } 2017 \mathrm{a} ;{ }^{3} \text { João } \\
\text { et al., } 2017\end{array}$ \\
\hline $\begin{array}{l}\text { Arachis oteroi Krapov. \& } \\
\text { W.C.Greg. }\end{array}$ & $\begin{array}{l}\text { amendoim } \\
\text { forrageiro } \\
\text { (mandui rã) }\end{array}$ & $\begin{array}{l}\mathrm{Ce} \\
(\mathrm{h})\end{array}$ & 0,2 & dor de dente & $\begin{array}{l}\mathrm{C} \\
\mathrm{R}\end{array}$ & Million, 2017 \\
\hline Bauhinia forficata Link & $\begin{array}{l}\text { pata de vaca } \\
\text { (pata de guei) }\end{array}$ & $\begin{array}{l}\text { M } \\
\text { (av) }\end{array}$ & 0,2 & emagrecer & $\mathrm{R}$ & Million, 2017 \\
\hline $\begin{array}{l}\text { Bauhinia rufa } \\
\text { (Bong.)Steud. }\end{array}$ & $\begin{array}{l}\text { pata-de-boi } \\
\text { (vacapo) }\end{array}$ & $\begin{array}{l}\mathrm{Ce} \\
(\mathrm{sa})\end{array}$ & 0,2 & $\begin{array}{l}\text { infecção } \\
\text { urinária }\end{array}$ & Fo & $\begin{array}{l}\text { Benites et al., } \\
2017 \mathrm{a}\end{array}$ \\
\hline $\begin{array}{l}\text { Copaifera langsdorffii } \\
\text { Desf. }\end{array}$ & $\begin{array}{l}\text { pau-de-óleo } \\
(k u p a ' y)\end{array}$ & $\begin{array}{l}\mathrm{Ca} / \mathrm{Ce} / \\
\mathrm{M} \\
(\mathrm{av})\end{array}$ & 0,4 & gripe, bronquite & $\mathrm{C}$ & Bueno et al., 2005 \\
\hline $\begin{array}{l}\text { Desmodium incanum } \\
\text { (Sw.) DC. }\end{array}$ & $\begin{array}{l}\text { pega-pega } \\
(\text { tatu po ju } \\
\text { pohã) }\end{array}$ & $\begin{array}{l}\mathrm{cv} \\
(\mathrm{sa})\end{array}$ & 0,2 & inflamações & $\mathrm{R}$ & Million, 2017 \\
\hline $\begin{array}{l}\text { Dimorphandra mollis } \\
\text { Benth. }\end{array}$ & $\begin{array}{l}\text { barbatimão } \\
\text { (loritopuisã) }\end{array}$ & $\begin{array}{l}\mathrm{A} / \mathrm{Ce} \\
\text { (av) }\end{array}$ & 0,2 & dor na coluna & $\mathrm{C}$ & Bueno et al., 2005 \\
\hline Dinizia excelsa Ducke & $\begin{array}{l}\text { angelim } \\
\text { (chiru) }\end{array}$ & $\begin{array}{l}\text { A } \\
\text { (av) }\end{array}$ & 0,2 & coceira & $\mathrm{R}$ & Rego et al., 2010 \\
\hline $\begin{array}{l}\text { Enterolobium } \\
\text { contortisiliquum } \\
\text { (Vell.)Morong }\end{array}$ & $\begin{array}{l}\text { orelha-de- } \\
\text { padre }^{1} \text {,timbori } \\
\left(\text { pa'i nambi }^{1} \text {, }\right. \\
\left.\text { timboy }^{2}\right)\end{array}$ & $\begin{array}{l}\mathrm{Ca} / \mathrm{Ce} / \\
\mathrm{M} \\
(\mathrm{av})\end{array}$ & 0,4 & $\begin{array}{l}\text { feridas }^{1}, \text { sarna }^{1}, \\
\text { coceiras }^{12}\end{array}$ & $\mathrm{C}^{12}$ & $\begin{array}{l}{ }^{1} \text { Lopes et al., } \\
2017 ;{ }^{2} \text { João et al., } \\
2017\end{array}$ \\
\hline $\begin{array}{l}\text { Enterolobium timbouva } \\
\text { Mart. }\end{array}$ & $\begin{array}{l}\text { orelha-de- } \\
\text { macaco } \\
\text { (petiỹ) }\end{array}$ & $\begin{array}{l}\mathrm{A} / \mathrm{Ca} / \\
\mathrm{Ce} / \mathrm{M} / \\
\mathrm{Pt} \\
\text { (av) }\end{array}$ & 0,2 & $\begin{array}{l}\text { cicatrizar o } \\
\text { umbigo de } \\
\text { bebes }\end{array}$ & $\mathrm{C}$ & João et al., 2017 \\
\hline Hymenaea courbaril L. & $\begin{array}{l}\text { jatobá } \\
\text { (jatayva) }\end{array}$ & $\begin{array}{l}\mathrm{A} / \mathrm{Ca} / \\
\mathrm{Ce} / \mathrm{M} / \\
\mathrm{Pt} \\
(\mathrm{av})\end{array}$ & 0,8 & $\begin{array}{l}\text { digestivo }^{1}, \\
\text { gripe }^{1}, \\
\text { revigorante }^{2}\end{array}$ & $\mathrm{C}^{12}$ & $\begin{array}{l}{ }^{1} \text { Bueno et al., } \\
\text { 2005; }{ }^{2} \text { João et al., } \\
2017\end{array}$ \\
\hline Inga sessiies (Vell.) Mart & $\begin{array}{l}\text { ingá } \\
(-)\end{array}$ & $\begin{array}{l}\mathrm{A} / \mathrm{Ce} / \\
\mathrm{M} \\
(\mathrm{av})\end{array}$ & 0,3 & $\begin{array}{l}\text { diarreia, dor de } \\
\text { barriga, cólica }\end{array}$ & $\mathrm{C}$ & $\begin{array}{l}\text { Benites et al., } \\
2017 \mathrm{a}\end{array}$ \\
\hline $\begin{array}{l}\text { Leptolobium elegans } \\
\text { Vogel }\end{array}$ & $\begin{array}{l}\text { perobnha-do- } \\
\text { campo } \\
\text { (perova'i) }\end{array}$ & $\begin{array}{l}\mathrm{Ce} \\
\text { (av) }\end{array}$ & 0,2 & sarna & $\mathrm{C}$ & Million, 2017 \\
\hline $\begin{array}{l}\text { Lonchocarpus sericeus } \\
\text { (Poir.) Kunth ex DC }\end{array}$ & $\begin{array}{l}\text { ingazeiro } \\
(\tilde{y} v y r a \text { pitã) }\end{array}$ & $\begin{array}{l}\mathrm{A} / \mathrm{Ca} / \\
\mathrm{Ce} / \mathrm{M} \\
(\mathrm{av})\end{array}$ & 0,5 & $\begin{array}{l}\text { dor degarganta, } \\
\text { dor de dente }\end{array}$ & $\mathrm{C}$ & Million, 2017 \\
\hline
\end{tabular}


Espaço Ameríndio

\begin{tabular}{|c|c|c|c|c|c|c|}
\hline $\begin{array}{l}\text { Machaerium aculeatum } \\
\text { Raddi. }\end{array}$ & $\begin{array}{l}\text { falso } \\
\text { barbatimão, } \\
\text { jacaranda-de- } \\
\text { espinho } \\
\text { (ukeri guaçu) }\end{array}$ & $\begin{array}{l}\mathrm{Ce} / \mathrm{M} / \\
\mathrm{Pt} \\
(1)\end{array}$ & 0,2 & hemorragia & $\mathrm{C}$ & $\begin{array}{l}\text { Benites et al., } \\
2017 \mathrm{a}\end{array}$ \\
\hline $\begin{array}{l}\text { Machaerium acutifolium } \\
\text { Vogel }\end{array}$ & $\begin{array}{l}\text { limãodocampo } \\
\text { (ysapy'y, } \\
\text { yvyraitamirĩ) }\end{array}$ & $\begin{array}{l}\mathrm{A} / \mathrm{Ca} / \\
\mathrm{Ce} / \mathrm{M} \\
(\mathrm{av})\end{array}$ & 0,2 & $\begin{array}{l}\text { inflamação na } \\
\text { garganta }\end{array}$ & $\mathrm{C}$ & João et al., 2017 \\
\hline $\begin{array}{l}\text { Machaerium amplum } \\
\text { Benth. }\end{array}$ & $\begin{array}{l}\text { maria preta } \\
\text { (nyuan gwe } \tilde{y})\end{array}$ & $\begin{array}{l}\mathrm{A} / \mathrm{Ce} / \\
\mathrm{M} \\
(\mathrm{ab})\end{array}$ & 0,5 & $\begin{array}{l}\text { dor no corpo, } \\
\text { cólica menstrual }\end{array}$ & $\mathrm{C}$ & Million, 2017 \\
\hline $\begin{array}{l}\text { Mimosa candolei } \\
\text { R.Grether }\end{array}$ & $\begin{array}{l}\text { dorme-dorme } \\
\text { (tamonge) }\end{array}$ & $\begin{array}{l}\mathrm{A} / \mathrm{Ca} / \\
\mathrm{Ce} / \mathrm{M} \\
\text { (h) }\end{array}$ & 0,2 & insônia & Fo & Million, 2017 \\
\hline $\begin{array}{l}\text { Peltophorum dubium } \\
\text { (Spreng.) Taub. }\end{array}$ & $\begin{array}{l}\text { canafístula } \\
\text { (yvirapitã) }\end{array}$ & $\begin{array}{l}\mathrm{Ca} / \mathrm{Ce} / \\
\mathrm{M} / \mathrm{Pt} \\
(\mathrm{av})\end{array}$ & 0,8 & $\begin{array}{l}\text { cicatrização de } \\
\text { ferida }^{12}, \\
\text { tuberculose }^{2}, \\
\text { sarna }^{3}, \text { coceira }^{3} \text {, } \\
\text { ferida na boca }^{4}\end{array}$ & $\begin{array}{l}\mathrm{C}^{14} \\
\mathrm{Fo}^{23}\end{array}$ & $\begin{array}{l}{ }^{1} \text { Bueno et al., } \\
\text { 2005; }{ }^{2} \text { Rego et al. } \\
\text { 2010; }{ }^{3} \text { Benites et } \\
\text { al., 2017a; } \\
{ }^{4} \text { Benites et al., } \\
2017 \text { b }\end{array}$ \\
\hline $\begin{array}{l}\text { Pterodon emarginatus } \\
\text { Vog. }\left[\text { Sucetiafruticosa }{ }^{2}\right.\end{array}$ & $\begin{array}{l}\text { sucupira } \\
\text { (yviraperó) }\end{array}$ & $\begin{array}{l}\mathrm{A} / \mathrm{Ca} / \\
\mathrm{Ce} / \mathrm{Pt} \\
(\mathrm{av})\end{array}$ & 1,2 & $\begin{array}{l}\text { dor de cabeça }{ }^{123} \text {, } \\
\text { dor de barriga }{ }^{2} \text {, } \\
\text { dor de } \\
\text { estômago }^{2} \text {, } \\
\text { febre }^{1}, \text { gripe }^{3} \text {, } \\
\text { dor no } \\
\text { corpo }^{3}, \text { tosse }^{3}\end{array}$ & $\begin{array}{l}\mathrm{C}^{23} \\
\mathrm{~S}^{12}\end{array}$ & $\begin{array}{l}{ }^{1} \text { Bueno et al., } \\
\text { 2005; }{ }^{2} \text { Rego et al., } \\
\text { 2010; }{ }^{3} \text { Benites et } \\
\text { al., } 2017 \text { a }\end{array}$ \\
\hline Pterogyne nitens Tul. & $\begin{array}{l}\text { amendoim } \\
\text { (anguaỹ) }\end{array}$ & $\begin{array}{l}\mathrm{Ca} / \mathrm{Ce} / \\
\mathrm{M} \\
(\mathrm{av})\end{array}$ & 0,2 & ferida & $\mathrm{C}$ & João et al., 2017 \\
\hline $\begin{array}{l}\text { Senna obtusifolia (L.) } \\
\text { H.S.Irwin \& Barneby }\end{array}$ & $\begin{array}{l}\text { cafezinho } \\
\text { (taperyva) }\end{array}$ & $\begin{array}{l}\mathrm{A} / \mathrm{Ca} / \\
\mathrm{Ce} / \mathrm{M} / \\
\mathrm{Pt} \\
(\mathrm{ab})\end{array}$ & 0,6 & $\begin{array}{l}\text { febre, dor no } \\
\text { corpo, diarreia }\end{array}$ & $\mathrm{R}$ & Million, 2017 \\
\hline $\begin{array}{l}\text { Stryphnodendron } \\
\text { adstringens } \\
\text { (Mart.)Coville }\end{array}$ & $\begin{array}{l}\text { barbatimão } \\
\text { (lorito pysã) }\end{array}$ & $\begin{array}{l}\mathrm{Ca} / \mathrm{Ce} \\
(\mathrm{ab})\end{array}$ & 1,5 & $\begin{array}{l}\text { sarna }^{13}, \text { coceira }^{1} \text {, } \\
\text { dor de } \\
\text { garganta }^{1}, \\
\text { ferida }^{123} \text {, } \\
\text { fortificar o } \\
\text { útero }^{1}, \text { diarreia }^{2} \text {, } \\
\text { DSTs }\end{array}$ & $\mathrm{C}^{123}$ & $\begin{array}{l}{ }^{1} \text { Million, } 2017 \text {; } \\
{ }^{2} \text { Lopes et } \\
\text { al.,2017; }{ }^{3} \text { Benites } \\
\text { et al., } 2017 \mathrm{a}\end{array}$ \\
\hline
\end{tabular}

IRIDACEAE

tryphnodendron
dstringens
Mart.)Coville

limãodocampo

$\mathrm{Ce} / \mathrm{M}$

inf

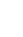


Espaço Ameríndio

(akãfor)

Leonurus sibiricus L.

Origanum vulgare L.

Plectranthus barbatus

Andrews

LAURACEAE

Ocotea corymbosa

(Meisn.) Mez.

Perseaamericana Mill.

(Ajuỹ)

abacate

$(-)$

rubim

$(-)$

mangerona

$(-)$

boldo

(bordo)

jequitibá (guaivi pire, ka'i ka'ygua)

LOGANIACEAE

Strychnos bicolorProgel

quina

(xirika'i)

LORANTHACEAE

Psittacanthus Mart. sp.

jequitibá ${ }^{1}$, erva de passarinho ${ }^{2}$ (guaivi pire, ka'i ka'ygua', japikoxireka ${ }^{2}$ ) (h)

cV

(h)

$\mathrm{cV}$

(h)

cv
0,4 diarreia, cólica,dor de estômago

$\mathrm{Ce} / \mathrm{M} \quad 0,2 \quad$ coceira

(av)

cv $\quad 0,2$ diabetes

(av)

$\mathrm{A} / \mathrm{Ce} / \quad 0,2$ dor de cabeça

(av)

$\mathrm{A} / \mathrm{Ce} /$

articulações, inalação para doenças respiratórias

0,2 cicatrizante

Fo

Benites et al., 2017 a

Benites et al., 2017 a

Fo Benites et al. 2017 a

C João et al., 2017

Fo Benites et al. 2017 a

$\mathrm{Ce} / \mathrm{M} \quad 0,5 \quad$ gripe, diarreia $\quad \mathrm{R}, \quad$ Million, 2017

(1) $\mathrm{M}$

(1)

0,5 dor de cabeça ${ }^{1}$, dor de estômago ${ }^{2}$

${ }^{1}$ Benites et al. $\mathrm{Fo}^{2} \quad 2017 \mathrm{~b} ;{ }^{2}$ João et al., 2017

Benites et al. $2017 b$

Fo

\section{LYCOPODIACEAE}

Lycopodiella cernua (L.) Pic. Serm. *[Palhinhaea

pinheirinho

$\mathrm{A} / \mathrm{Ce} /$

0,2 fertilidade

$\mathrm{R}$ cernua (L.)Franco $\mathrm{M} / \mathrm{Pa} /$ feminina

LYTHRACEAE

Lafoensia pacari A. St.-

pacuri

$(-)$

$\mathrm{Ce}$

0,2 pneumonia

$\mathrm{Fr}$

Bueno et al., 2005

Hil

(av)

\section{MALPIGHIACEAE}

Banisteriopsis C.B.Rob.

cipó-prata ex Small sp. (isipo aysỹ)

$\mathrm{A} / \mathrm{Ca} / \quad 0,2$ berne

João et al., 2017

(ab)

Heteropterys tomentosa nó-de-cachorro $(-)$

\section{(1)}

Million, 2017 A. Juss. *[Heteropterys aphrodisiaca O. Mach.] 
Espaço Ameríndio

MALVACEAE

Byttneria scalpellata

Pohl

Luehea grandiflora

Mart.\& Zucc.

Guazuma ulmifolia Lam.

Waltheria indica L. (pikatĩ)

$\mathrm{Ce}$

(h)

açoita cavalo

(yvyra rogue

guaçu ${ }^{1}$, kaovet ${ }^{2}$

$\mathrm{A} / \mathrm{Ca} /$

$\mathrm{Ce} / \mathrm{M} /$

$\mathrm{Pt}$

(av)

Guazuma ulmifolia Lam. mutambo (gua'a resay)

$\mathrm{A} / \mathrm{Ca} /$

$\mathrm{Ce} / \mathrm{M}$

(av)

douradinhadoce

rrado

(rogue morote

i'a)

$\mathrm{A} / \mathrm{Ca} /$

$\mathrm{Ce} / \mathrm{M} /$

$\mathrm{Pt}$

(sa)

\section{MARANTACEAE}

Goeppertia sellowii

(Körn.) Borchs.

\&S.Suárez

caeté

(pariri y'já)

$\mathrm{Ce} / \mathrm{M}$

(h)

$\mathrm{A} / \mathrm{Ce} /$

(hapo apu'ava)

$\mathrm{M}$

(sa)

Miconia albicans (Sw.)

Triana

quaresmeira

(pãraey porã)

$\mathrm{A} / \mathrm{Ca} /$

$\mathrm{Ce} / \mathrm{M}$

(ab)

quaresmeira

(mba'e gwa)

Rhynchanthera
dichotoma (Desr.) DC
$\mathrm{A} / \mathrm{Ce} /$

$\mathrm{M}$

(ab)
$0,6 \quad$ cólica
menstrual,
gases, diarreia

1,0 infecção na

urina $^{1}$, ácido

úrico ${ }^{1}$,

reumatismo ${ }^{1}$,

diarreia $^{1}$, ferida $^{2}$

0,5 ferida na boca, C

inflamação de

garganta

0,2 câncer de colo de útero

$\mathrm{R}$

R, Million, 2017

Fo

$\mathrm{Fo}^{1}, \quad{ }^{1}$ Benites et al.,

$\mathrm{C}^{12}$ 2017a; ${ }^{2}$ João et al., 2017

C Benites et al., 2017b

Benites et al., $2017 \mathrm{a}$
Fo, Million, 2017

$\mathrm{R}$

coagulador $\mathrm{de}$

sangue, dor de

barriga

0,2 dor no útero

$\mathrm{R}$

Million, 2017

Fo Benites et al., 2017a

(ago,

problema de

fígado

0,2 inflamação no

útero

R Million, 2017

\section{MELIACEAE}

Cabralea canjerana

(Vell.) Mart.

Cedrela fissilis Vell.

cedro

(yary $1 /$ yuyrakati

$n g y^{2}$, seyro $^{3}$ )
$\mathrm{A} / \mathrm{Ca} /$

$\mathrm{Ce} / \mathrm{M}$

(av)

$\mathrm{A} / \mathrm{Ce} /$

$\mathrm{M}$

(av)

Melia azedarach L.

$$
\begin{aligned}
& \text { cinamono } \\
& \text { (paraíso) }
\end{aligned}
$$

$\mathrm{A} / \mathrm{Ca} /$
$\mathrm{Ce} / \mathrm{M}$
$(\mathrm{av})$
0,5 doenças da pele ${ }^{1}$, dor de barriga $^{2}$

1,6 gripe $^{12}$, dor de cabeça $a^{14^{35}}$, dor de garganta ${ }^{2}$, febre ${ }^{24}$, cólica $^{3}$, dor de estômago $^{3}$, reumatismo ${ }^{5}$

0,3 regular a menstruação, hemorragia menstrual
$\mathrm{C}^{12} \quad{ }^{1}$ Bueno et al., 2005; ${ }^{2}$ Benites et al., $2017 \mathrm{~b}$

$\mathrm{C}^{12345}{ }^{1}$ Bueno et al., 2005; ${ }^{2}$ Million, 2017; ${ }^{3}$ Benites et al., 2017a; ${ }^{4}$ Benites et al., 2017b; ${ }^{5}$ João et al., 2017

Fo João et al., 2017 
Espaço Ameríndio

MENISPERMACEAE

Cissampelos ovalifolia

DC.

orelha-de-onça $\mathrm{A} / \mathrm{Ca} /$

(gwavira)

$\mathrm{Ce} / \mathrm{M} /$

$\mathrm{Pt}$

(h)

Cissampelos pareira L.
$\mathrm{A} / \mathrm{Ca} /$

$\mathrm{Ce} / \mathrm{M} /$

$\mathrm{Pa} / \mathrm{Pt}$

(1)
0,3 dor de barriga, Fo Million, 2017

diarreia

0,2 dor de coluna Fo

Million, 2017

\section{MORACEAE}

Dorstenia brasiliensis

Lam.

Ficus inspida Willd.

Maclura tinctoria (L.)

D.Don ex Steud.

Morus nigra L.

MUSACEAE

Musa paradisiaca L.

banana

(pacova karape)

MYRSINACEAE

Myrsine coriacea (Sw.) pororoca

R.Br. ex Roem. \&

(yvirare)

Schult. *[Rapanea

ferruginea (Ruiz et

Pav.)]

MYRTACEAE

$\begin{array}{ll}\begin{array}{l}\text { Campomanesia } \\ \text { adamantium (Cambess.) } \\ \text { Berg }\end{array} & \begin{array}{l}\text { guavira }^{12}, \\ \text { guavira } \\ \text { vermelha }^{3} \\ \text { (gwavira ipoty }^{1}, \\ \text { guavira pyta }{ }^{23} \text { ) }\end{array} \\ & \text { sete capote } \\ \text { Campomanesia } & \text { (guavirá) } \\ \text { Xanthocarpa (Mart.) } & \end{array}$

$\mathrm{A} / \mathrm{Ca} /$

$\mathrm{Ce} / \mathrm{M} /$

$\mathrm{Pa} / \mathrm{Pt}$

(h)

A

(av)

$\mathrm{A} / \mathrm{Ca} /$

$\mathrm{Ce} / \mathrm{M} /$

$\mathrm{Pa} / \mathrm{Pt}$

(av)

amora

(amora)

$\mathrm{cV}$

(av)

0,2 ferida na boca

Sv

João et al., 2017

feridas ${ }^{123}$, reumatismo
caxumba $^{2}$

$\mathrm{C}^{12}, \quad{ }^{1}$ Bueno et al., $\mathrm{Fo}^{12}, \quad 2005 ;{ }^{2}$ Benites et $\mathrm{Sv}^{3}$ al., 2017a; ${ }^{3}$ João et al., 2017

0,2 dor de dente

$\mathrm{C}$

Bueno et al., 2005

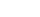

Ce/M $\quad 0,8 \quad$ dor de barriga ${ }^{12}, \quad \mathrm{R}^{1}, \quad{ }^{1}$ Million, 2017;

(ab) dor de $\mathrm{Fo}^{2}, \quad{ }^{2}$ Benites et al., estômago ${ }^{1}, \quad \mathrm{C}^{2}, \quad 2017 \mathrm{a} ;{ }^{3}$ João et pele ${ }^{13}$, cólica $^{2}, \quad \mathrm{Fr}^{3} \quad$ al., 2017 diarreia $^{2}$

$\mathrm{Ce} / \mathrm{M}$
$(\mathrm{av})$

diarreia $^{12}$, vômito $^{1}$, dor de barriga $^{1}$, dor no estômago ${ }^{2}$
$\mathrm{Fo}^{1}, \quad{ }^{1}$ Benites et al., $\mathrm{C}^{2} \quad 2017 \mathrm{a} ;{ }^{2}$ Benites et al., 2017b 
Espaço Ameríndio

\begin{tabular}{|c|c|c|c|c|c|c|}
\hline Eucalyptus L'Hér. sp. & $\begin{array}{l}\text { eucalipto } \\
\text { (kalipio) }\end{array}$ & $\begin{array}{l}\mathrm{cv} \\
\text { (av) }\end{array}$ & 1,1 & $\begin{array}{l}\text { febre, vômito, } \\
\text { cólica, gripe, } \\
\text { tosse, dor de } \\
\text { cabeça }\end{array}$ & Fo & $\begin{array}{l}\text { Benites et al., } \\
2017 \mathrm{a}\end{array}$ \\
\hline Eugenia florida DC. & $\begin{array}{l}\text { pitanga } \\
\text { (kururu) }\end{array}$ & $\begin{array}{l}\mathrm{A} / \mathrm{Ca} \\
/ \mathrm{Ce} / \mathrm{M} \\
(\mathrm{av})\end{array}$ & 0,2 & diarreia & $\mathrm{C}$ & $\begin{array}{l}\text { Benites et al., } \\
2017 \mathrm{~b}\end{array}$ \\
\hline Eugenia uniflora L. & $\begin{array}{l}\text { pitanga-mirim } \\
\text { (pitanga'i) }\end{array}$ & $\begin{array}{l}\mathrm{Ce} / \mathrm{M} / \\
\mathrm{Pa} \\
(\mathrm{ab})\end{array}$ & 0,4 & $\begin{array}{l}\text { dor de } \\
\text { estômago }^{1} \text {, } \\
\text { diarreia }^{12} \text {, } \\
\text { vômito }^{2}\end{array}$ & $\begin{array}{l}\mathrm{Fo}^{12} \\
\mathrm{C}^{12}, \mathrm{~B}\end{array}$ & $\begin{array}{l}{ }^{1} \text { Bueno et al., } \\
\text { 2005; }{ }^{2} \text { Benites et } \\
\text { al., } 2017 \mathrm{a}\end{array}$ \\
\hline $\begin{array}{l}\text { Myrcia anomala } \\
\text { Cambess. }\end{array}$ & $\begin{array}{l}\text { - } \\
\text { (tejo guassu } \\
\text { pohã) }\end{array}$ & $\begin{array}{l}\mathrm{Ce} / \mathrm{M} / \\
\mathrm{Pa} \\
(\mathrm{ab})\end{array}$ & 0,2 & $\begin{array}{l}\text { cólica em } \\
\text { gestante }\end{array}$ & $\begin{array}{l}\text { Fo, } \\
\text { R }\end{array}$ & Million, 2017 \\
\hline $\begin{array}{l}\text { Myrcianthes pungens (O. } \\
\text { Berg) D. Legrand }\end{array}$ & $\begin{array}{l}\text { guavira-guaçu } \\
\text { (guavira }^{1} \\
\left.\text { guaviju }^{2}\right)\end{array}$ & $\begin{array}{l}\mathrm{Ce} / \mathrm{M} \\
\text { (av) }\end{array}$ & 0,3 & $\begin{array}{l}\text { dor abdominal }^{1} \text {, } \\
\text { dor de } \\
\text { estômago }^{2}\end{array}$ & $\mathrm{C}^{12}$ & $\begin{array}{l}{ }^{1} \text { Bueno et al., } \\
2005 ;{ }^{2} \text { João et al., } \\
2017\end{array}$ \\
\hline Psidium guajava L. & $\begin{array}{l}\text { goiaba } \\
\left(\text { araça }^{1} \text {, araça }\right. \\
\left.\text { poty }^{2}\right)\end{array}$ & $\begin{array}{l}\mathrm{A} / \mathrm{Ca} / \\
\mathrm{Ce} / \mathrm{M} \\
\text { (av) }\end{array}$ & 0,4 & $\begin{array}{l}\text { diarreia }^{1}, \\
\text { vômito }^{1} \text {, dor de } \\
\text { barriga }^{2}\end{array}$ & $\begin{array}{l}\mathrm{Fo}^{1} \\
\mathrm{C}^{1} \\
\mathrm{Fl}^{2}\end{array}$ & $\begin{array}{l}{ }^{1} \text { Bueno et al., } \\
\text { 2005; }{ }^{2} \text { Benites et } \\
\text { al., } 2017 \mathrm{a}\end{array}$ \\
\hline
\end{tabular}

OCHNACEAE

Sauvagesia racemosa

A.St.-Hil

erva-de-são

martinho

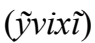

$\mathrm{Ce} / \mathrm{M}$

(h)

\section{ORCHIDACEAE}

Catasetum Rich. ex

Kunth sp.

orquídea

terrestre

(pako'ai)

orquídea

Oeceoclades maculata

(Lindl.) Lindl.
$\mathrm{A} / \mathrm{Ca} /$

$\mathrm{Ce} / \mathrm{M} /$

$\mathrm{Pa} / \mathrm{Pt}$

(1)

$\mathrm{A} / \mathrm{Ca} /$

$\mathrm{Ce} / \mathrm{M}$

(1)
0,2 dilatador no

parto
Fo $\quad$ Million, 2017

Milion, 2017

\section{OXALIDACEAE}

Oxalis L. sp.

trevinho

(mandu'i)

$\mathrm{A} / \mathrm{Ca} /$

0,2 cólica menstrual Fr

Benites et al., $\mathrm{Ce} / \mathrm{M} /$ 2017a

$\mathrm{Pa} / \mathrm{Pt}$

PASSIFLACEAE

Passiflora L. sp.

maracujá do
mato
(mburukujá)

$\mathrm{A} / \mathrm{Ca} /$

0,53 calmante, controle de pressão alta

Fl, $\quad$ Lopes et al., 2017

Fr,

Fo

Benites et al. 2017a

Million, 2017 útero, infecção urinária

PHYLLANTHACEAE

Phyllanthus tenellus

quebra pedra (paraparai)

$\mathrm{A} / \mathrm{Ca} / \quad 0,2 \quad$ diabetes
$\mathrm{Ce} / \mathrm{M}$
$(\mathrm{ab})$


Espaço Ameríndio

PHYTOLACCACEAE

Petiveria alliacea L. $\begin{array}{ll}\text { guiné } & \mathrm{cv} \\ \text { (pikatĩ) } & \text { (sa) }\end{array}$
1,1 picada de
cobra $^{14}$, tosse ${ }^{1}$, dor muscular ${ }^{1}$, dor nas articulações ${ }^{1}$, dor de cabeça ${ }^{2}$, cãibras $^{3}$

\section{PIPERACEAE}

Piper amalago L.

Piper aduncum L. *[ Piper angustifolium Lam.]

$\begin{array}{ll}\begin{array}{l}\text { falso jaborandi } \\ \text { (ka'a hogue ne) }\end{array} & \begin{array}{l}\mathrm{A} / \mathrm{Ca} / \\ \mathrm{Ce} / \mathrm{M} \\ (\mathrm{ab})\end{array} \\ \begin{array}{ll}\text { pariparoba } \\ \text { (pariparova) }\end{array} & \begin{array}{l}\mathrm{A} / \mathrm{Ca} / \\ \mathrm{Ce} / \mathrm{M} / \\ \mathrm{Pa} / \mathrm{Pt} \\ (\mathrm{ab})\end{array} \\ & \mathrm{A} / \mathrm{Ce} / \\ \text { pariparoba } & \mathrm{M}\end{array}$

(sa)

0,4 gripe, dor de cabeça, febre

Fo Bueno et al., 2005

$\mathrm{Fo}^{123}, \quad{ }^{1}$ Bueno et al., 2005; ${ }^{2}$ Lopes et al., 2017; ${ }^{3}$ Benites et al., 2017a; ${ }^{4}$ João et al., 2017

C

Benites et al., 2017a

\section{*[Pothomorphe} umbellata Miq.]

\section{PLANTAGINACEAE}

\section{Plantago tomentosa}

Lam.

POACEAE

Cymbopogon citratus (DC.) Stapf.

Digitaria insularis (L.) Fedde

\section{Imperata brasiliensis Trin.}

\section{Olyra ciliatifolia Raddi}

Pharus lappulaceus Aubl.

$$
\begin{aligned}
& \text { capim cidreira } \\
& \left.{\text { (ka'a kapi' }{ }^{1} \text {, }}^{\text {' }} \text { kapi'isedron }{ }^{2}\right)
\end{aligned}
$$

\section{0,5}

antitabagismo antobiótico

S

Benites et al., $2017 \mathrm{a}$

cv
(h)

cv

\section{1,}

calmante $^{1}$, dor

$\mathrm{Fo}^{12}, \quad{ }^{1}$ Lopes et al., de estômago ${ }^{1}$, dor de cabeça ${ }^{1}$, al., 2017a cólica de fígado ${ }^{1}$, vômito ${ }^{2}$, gripe ${ }^{2}$, tosse $^{2}$, febre $^{2}$, resfriado $^{2}$

capim amargoso cv (kapii pororó)

sapé

(sapé)

$\mathrm{A} / \mathrm{Ca} /$

$\mathrm{Ce} / \mathrm{M} /$ $\mathrm{Pa} / \mathrm{Pt}$

(h)

0,5 antibiótico, sangue

0,6 DSTs, infecção urinária $^{12}$, infecção no útero $^{1}$

\section{canilhas} (pariri'i)

$\mathrm{A} / \mathrm{Ca} /$ $\mathrm{Ce} / \mathrm{M} /$ $\mathrm{Pt}$

(h)

capim bambu (ka'iaró)

0,2 cicatrizanteumbi Fo go de recém nascido

\section{0,2 cicatrizante, $\quad$ Fo} umbigo de
$\mathrm{A} / \mathrm{Ca} /$ $\mathrm{Ce} / \mathrm{M}$ (h) coagulador de

Million, 2017

$\mathrm{R}^{1} \quad 2017 ;{ }^{2}$ Benites et

Fo Million, 2017

Fo $^{1}, \quad{ }^{1}$ Million, 2017;

$\mathrm{R}^{2} \quad{ }^{2}$ João et al., 2017

Million, 2017

Million, 2017 recém nascido 
Espaço Ameríndio

POLYPODIACEAE

Pleopeltis polypodioides

(L.) E.G. Andrews \&

Windham

Polygonum

hydropiperoides Michx.

erva de bicho

(vicho ka'a)

Polypodium L. sp.

Serpocaulon latipes

(Langsd. \& L.

Fisch.)A.R. Sm.

PRIMULACEAE

Clavija nutans (Vell.)

B.Ståhl

(kalaguala)

$\mathrm{A} / \mathrm{Ce} /$

$\mathrm{A} / \mathrm{Ce} /$

0,2 emagrecer

R, Million, 2017

$\mathrm{M}$

(h)

$\mathrm{Ca} / \mathrm{Ce} / \quad 0,5 \quad$ sarna, coceira,

$\mathrm{M} / \mathrm{Pt} \quad$ frieira, chulé

PI

Lopes et al., 2017

(h)

$\mathrm{M}$

(h)

$\mathrm{Ca} / \mathrm{Ce} /$

(karaguara)

$\mathrm{M} / \mathrm{Pt}$

(h)
0,3 cicatrizante,
depurativo pós
parto

$\mathrm{R}$

Benites et al., $2017 \mathrm{a}$

$\mathrm{R}$

Million, 2017

inflamatório,

pós parto

$\mathrm{Ce} / \mathrm{M} \quad 0,3$ purificação de

(ab) sangue, útero

Fo

Million, 2017 chá de bugre,

porangaba

(karumbe yua)

\section{RUBIACEAE}

Alibertia edulis (Rich.)

A. Rich ex DC.

marmelo-de-

cerrado

(asuka revire)

Borreria verticillata (L.)

G.Mey.

erva-de-botão

(typyixa

tapekwe)

Coussarea

hydrangeifolia

(Benth.)Müll. Arg.

chá paraguaio, marmelada de cachorro

(ka'agwyryak $w \tilde{a})$

Genipa americana L.

$$
\begin{aligned}
& \text { jenipapo } \\
& (\text { mandy } p a)
\end{aligned}
$$

Geophila repens (L.)

I.M.Johnst

cauá pini

(aguape'i)

Randia armata (Sw.)

DC.

(

Tocoyena formosa

(Cham. \& Schltdl.)

K.Sch

trombeta

(memby e' yja) inflamado,

DSTs

$\mathrm{A} / \mathrm{Ce}$

0 ,

(ab)

$\mathrm{A} / \mathrm{Ca} /$

$\mathrm{Ce} / \mathrm{M}$

(sa)

\section{$\mathrm{A} / \mathrm{Ca} /$}

$\mathrm{Ce} / \mathrm{M}$

(ab)

Fr

Benites et al., 2017a

$\mathrm{R}$

Million, 2017

de barriga

vômito

Fo $\quad$ Million, 2017
$\mathrm{A} / \mathrm{Ca} /$

$\mathrm{Ce} / \mathrm{M} /$

$\mathrm{Pt}$

(av)

$\mathrm{A} / \mathrm{Ca} /$

$\mathrm{Ce} / \mathrm{M}$

(h)

$\mathrm{A} / \mathrm{Ca} /$

$\mathrm{Ce} / \mathrm{M}$

0,5 feridas,

disenteria

$\mathrm{R}$

$\mathrm{Fr}^{1}$,

$\mathrm{Fo}^{2}$

vermífugo,

vômito

(ab)

$\mathrm{A} / \mathrm{Ca} /$

$\mathrm{Ce} / \mathrm{M}$

0 ,

2

anticonceptivo

feminino

Fr, Million, 2017

Fo

depressão de

criança

(ab)

\section{RUTACEAE}


Espaço Ameríndio

\begin{tabular}{|c|c|c|c|c|c|c|}
\hline $\begin{array}{l}\text { Balfourodendron } \\
\text { riedelianum (Engl.)Engl. }\end{array}$ & $\begin{array}{l}\text { pau marfim }{ }^{1}, \\
\text { guatambú }^{2} \\
\text { (yvyra } \\
\text { ovi }^{1} \text {,yvyra ñetî) }\end{array}$ & $\begin{array}{l}\mathrm{Ce} / \mathrm{M} \\
\text { (av) }\end{array}$ & 0,5 & $\begin{array}{l}\text { sarna }^{1}, \text { ferida } \\
\end{array}$ & $\begin{array}{l}\mathrm{Fo}^{1} \\
\mathrm{C}^{2}\end{array}$ & $\begin{array}{l}{ }^{1} \text { Million, 2017; } \\
{ }^{2} \text { Benites et al., } \\
2017 \mathrm{~b}\end{array}$ \\
\hline Citrus aurantium L. & $\begin{array}{l}\text { laranja azeda } \\
\text { (naranhã hai) }\end{array}$ & $\begin{array}{l}\mathrm{cv} \\
(\mathrm{av})\end{array}$ & 0,2 & gripe & Fr & $\begin{array}{l}\text { Benites et al., } \\
2017 \mathrm{a}\end{array}$ \\
\hline Citrus limon (L.) Osbeck & $\begin{array}{l}\operatorname{limão} \\
(-)\end{array}$ & $\begin{array}{l}\mathrm{cv} \\
(\mathrm{av})\end{array}$ & 0,3 & gripe, tosse & $\begin{array}{l}\text { Fo, } \\
\text { Fr }\end{array}$ & $\begin{array}{l}\text { Benites et al., } \\
2017 \mathrm{a}\end{array}$ \\
\hline $\begin{array}{l}\text { Ertela trifolia }(\mathrm{L} .) \\
\text { Kuntze }\end{array}$ & $\begin{array}{l}\text { maricutinha, } \\
\text { alfavacade } \\
\text { cupim } \\
(\text { tupã syka'a) }\end{array}$ & $\begin{array}{l}\mathrm{A} / \mathrm{Ca} \\
/ \mathrm{Ce} / \mathrm{M} \\
\text { (sa) }\end{array}$ & 0,2 & dor de estômago & Fo & Million, 2017 \\
\hline Helietta apiculata Benth. & $\begin{array}{l}\text { canela-de-veado } \\
\text { (yvira ovi) }\end{array}$ & $\begin{array}{l}\mathrm{Ce} / \mathrm{M} \\
\text { (av) }\end{array}$ & 0,2 & $\begin{array}{l}\text { cicatrização de } \\
\text { feridas }\end{array}$ & $\mathrm{C}$ & Bueno et al., 2005 \\
\hline
\end{tabular}

\section{SALICACEAE}

Casearia

pau vidro

gossypiospermaBriq.

(tembeta' $y$ )

$\mathrm{A} / \mathrm{Ce} /$

0,2 vermicida

Fo

Benites et al.,

(av)

\section{SAPINDACEAE}

Allophylus edulisHieron. cocum

ex Niederl

(kunkum)
$\mathrm{A} / \mathrm{Ca} /$
$\mathrm{Ce} / \mathrm{M} /$
$\mathrm{Pt}$

(av)
1,1 controle de pressão alta ${ }^{1}$, cicatrizante de feridas, coceira ${ }^{1}$, diurético ${ }^{2}$, aperiente $^{2}$

\section{SAPOTACEAE}

Pouteria ramiflora (Mart.) Radlk.

curriola (yva guasu)

$\mathrm{A} / \mathrm{Ca} /$ $\mathrm{Ce} / \mathrm{M}$ (av)
$\mathrm{Fo}^{12} \quad{ }^{1}$ Lopes et al., 2017; ${ }^{2}$ Benites et al., $2017 \mathrm{a}$

\section{SIPARUNACEAE}

Siparuna guianensis

Aubl. limão bravo (tatukati)

\section{$\mathrm{A} / \mathrm{Ca} /$ \\ $\mathrm{Ce} / \mathrm{M} /$ \\ $\mathrm{Pt}$}

(ab)

\section{SMILACACEAE}

Smilax fluminensis Steud. salsaparilha

Benites et al.,

Smilax goyazana A.DC.
(nhuã pekã)

Smilax japicanga Griseb. salsaparilha
$\mathrm{Ca} / \mathrm{Ce} /$
$\mathrm{Pt}$

(sa)
0,2 dificuldade para $\mathrm{R} \quad$ João et al., 2017 urinar

0,3 diurético, limpa $\mathrm{R}$ os rins

Million, 2017
0,3 dor na coluna, Fo dor em geral
Fo $\quad$ Million, 2017
Benites et al., 2017a 
Espaço Ameríndio

SOLANACEAE

Solanum americanum

Mill.

Solanum bonariense L.

jurubeba brava

(-)

(ab)

Solanum mauritianum

Scop. *[Solanum

erianthum D. Don]

jurubeba ${ }^{1}$, fumo bravo $^{2}$

(katingua ${ }^{1}$,kaove

$\left.t i^{2}\right)$

Solanum palinacanthum

juá1, jurubeba² (juá ${ }^{1}, \tilde{a} y r a \tilde{n} a p a w$ $\left.{ }^{2}\right)$

$\mathrm{A} / \mathrm{Ca} /$

$\mathrm{Ce} / \mathrm{M} /$

$\mathrm{Pa} / \mathrm{Pt}$

(ab)

Solanum paniculatum L

jurubeba

(nhatiatã)

$\mathrm{A} / \mathrm{Ca} /$

$\mathrm{Ce} / \mathrm{M}$

(ab)

Solanum scuticum

M.Nee

jurubeba

(aguara yva)

Solanum subinerme Jacq

juúna

(yvyra vevui)
$\mathrm{A} / \mathrm{Ce} /$

$\mathrm{M}$

(ab)

$\mathrm{A} / \mathrm{Ce}$

(ab)
1,0 dor de dente ${ }^{1}$,

inchaço ${ }^{1}$,

ferida $^{23}$,

furúnculo de

pele $^{2}$, coceira $^{3}$

0,3 feridas na boca, Fo dor de garganta

0,5 inibe a vontade de beber ${ }^{1}$, infecção

urinária $^{2}$

0,8 tumor $^{1}$, feridas $^{1}, \quad \mathrm{Fr}^{1}$, dor nas costas $\quad \mathrm{Fo}^{2}$ associada à gripe $^{2}$

0,8 dor de barriga, ressaca, rim

Fo

0,3 ressaca, fígado

0,2 inflamação de garganta
Million, 2017

$\mathrm{R}$

Million, 2017

$\mathrm{Fr}^{1}, \quad{ }^{1}$ Million, 2017;

$\mathrm{Fo}^{2} \quad{ }^{2}$ Lopes et al., 2017

Benites et al., 2017a

${ }^{1}$ Million, 2017;

${ }^{2}$ João et al., 2017

${ }^{1}$ Million, 2017;

${ }^{2}$ Benites et

al.,2017a

C Million, 2017

URTICACEAE

Cecropia pachystachya Trécul

Urera aurantiaca Wedd

Urera baccifera (L.)

Gaudich. ex Wedd

Urtica dioica $\mathrm{L}$.

Urtica urens L. embaúba, lixa

demacaco

(ka'i pokova', amba'yru'ãgue )

$\mathrm{A} / \mathrm{Ca} /$ $\mathrm{Ce} / \mathrm{M} /$ $\mathrm{Pt}$ (av)

urtiguinha (pyno’y)

$\mathrm{A} / \mathrm{Ce} /$

$\mathrm{M}$

(ab)

urtiga

(pynõ)

$\mathrm{A} / \mathrm{Ca} /$

$\mathrm{Ce} / \mathrm{M}$

(ab)

urtiga

(pynõ)

urtiga-do-campo

(-)
0,8 ardência $^{1}$, vermelhidão nos olhos $^{1}$, dor de garganta ${ }^{2}$, conjuntivite ${ }^{3}$, dor nos olhos ${ }^{4}$

0,4 DSTs, infecção no aparelho genital feminino, cólica menstrual 0,5 dor de coluna, $\mathrm{R} \quad$ Million, 2017 gonorreia

$\mathrm{R}$,

$\quad$ Lopes et al., 2017 Fo

$\mathrm{C}^{12}, \quad{ }^{1}$ Million, 2017;

$\mathrm{Fo}^{24}{ }^{2}$ Benites et al., 2017a; ${ }^{3}$ Benites et al., 2017b; ${ }^{4}$ João et al., 2017

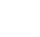

0,3 DSTs, doenças $\quad \mathrm{R}$, Lopes et al., 2017 do rim, fígado, vesícula

0,2 contra o berne $\quad \mathrm{R}$ (Dermatobia hominis L.)

Bueno et al., 2005 
Espaço Ameríndio

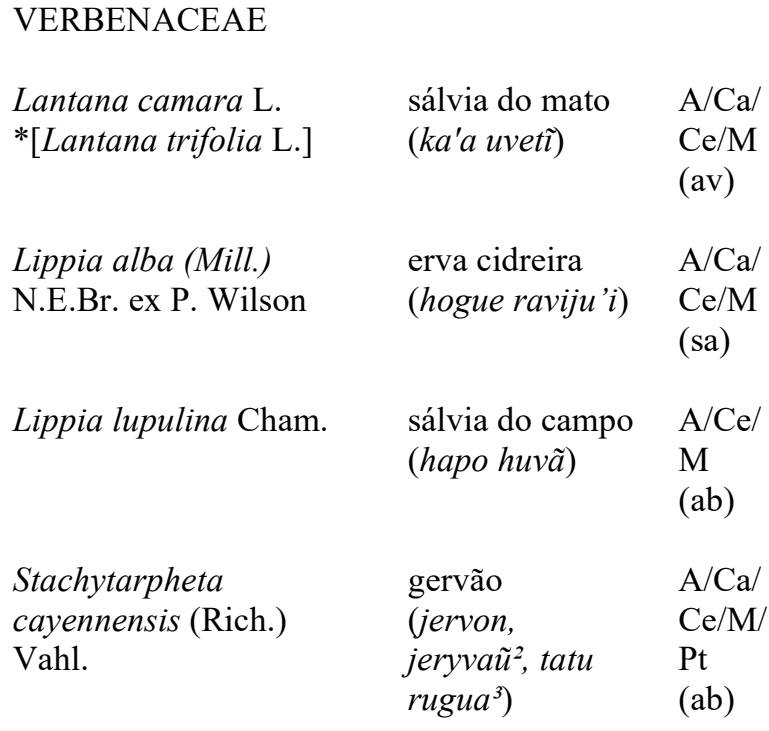

Verbena litoralis Kunth. gervão branco (-)

(h)

$\mathrm{ab}$

$\mathrm{A} / \mathrm{Ca} /$
$\mathrm{A} / \mathrm{Ca} / \quad 0,2$ inflamação do $\quad$ Fo

útero

0,3 dor de barriga, Fo

dor de estômago

0,3 dor de barriga, $\mathrm{R}$

vômito

Million, 2017

1,2 dor de estômago ${ }^{1}$, dor de coluna ${ }^{1}$, anestesia $^{2}$, feridas ${ }^{2}$, quebraduras $^{2}$, hemorragia menstrual $^{2}$, machucaduras internas $^{3}$

\section{0,4 dor no} estômago, digestivo, vesícula

$$
\begin{array}{ll}
\text { C, } & { }^{1} \text { Bueno et al., } \\
\text { R, } & \text { 2005; }{ }^{2} \text { Million, } \\
\text { Fo }^{123} & \begin{array}{l}
2017 ;{ }^{3} \text { Benites et } \\
\end{array} \\
& \text { al., } 2017 \mathrm{a}
\end{array}
$$

Fo

Benites et al., $2017 \mathrm{a}$

\section{VITACEAE}

Cissus L. sp. $\overline{(j y ' y)}$

Benites et al., $\mathrm{Pt} / \mathrm{Pa}$ 2017a

\section{ZINGIBERACEAE}

Curcuma L.sp.

(pariri)

cv

(h)
0,2 hemorragia em $\mathrm{R}$ mulheres
Benites et al., $2017 \mathrm{a}$

A (Amazônia); Ca (Caatinga); Ce (Cerrado); M (Mata Atlântica); Pa (Pampa), Pt (Pantanal).

C (casca); Fo (folha); Fr (fruto); PI (planta inteira); R (raiz); S (semente); Sv (seiva). av (arbóreo); ab (arbustivo); sa (subarbustivo); 1 (liana), h (herbáceo).

Os nomes científicos em colchetes se referem às espécies cujos nomes científicos desatualizados das plantas citadas. Os números sobrescritos correspondem ao número sobrescrito da respectiva referência.

Fonte: Elaboração própria.

O número de plantas medicinais citadas nas publicações analisadas variou de 10 (REGO et al., 2010) a 106 (MILLION, 2017). Fabaceae se destacou como sendo a família mais rica (27spp.), seguida pelas famílias Myrtaceae (8 spp.), Solanaceae (7 spp.) e Rubiaceae (7 spp.). Essas famílias juntas representam aproximadamente um quarto (24\%) de todas as espécies registradas nos estudos analisados, ou seja, das 73 famílias registradas nos estudos, quatro representam um quarto de todas as espécies encontradas, confirmando a importância dessas famílias na medicina tradicional guarani e kaiowá. Os gêneros mais ricos em espécies 
foram Solanum (sete spp.); Gomphrena, Machaerium, Piper, Smilax (três spp. cada), todos abrigando espécies exclusivamente nativas.

Nesse sentido, é importante ressaltar que essas quatro famílias cuja riqueza florística merece destaque são bastante comuns na Mata Atlântica (HANAZAKI et al., 2000; DI STASI et al., 2002; GAZZANEO et al., 2005), bioma predominante no território indígena em questão (COLMAN e PEREIRA, 2020). Essas famílias também são encontradas entre os grupos mais representativos em estudos etnobotânicos brasileiros de outros biomas como o Cerrado (AMOROZO, 2002) e a Floresta Amazônica (RODRIGUES, 2006).

\section{Importância relativa das espécies}

Do número total de espécies encontradas, 14,3\% (30 spp.) eram cultivadas e, em média, as nativas demonstraram uma IR mais alta (média: 0,8; DP: 0,5 ) do que as plantas cultivadas (média: 0,4; DP: 0,4). Nesta pesquisa, apenas 26 espécies demonstraram valores de IR iguais ou superiores a 1,0 (dentre essas, três eram cultivadas). No entanto, dessas espécies de plantas com importância relativa elevada (acima de 1,0 ), apenas 10 foram listadas nos trabalhos de Carneiro e dos Santos (2013, 2014) que reuniram as plantas medicinais da flora do centro oeste do Brasil, de forma que as outras 16 espécies de alta importância relativa não foram mencionadas nessas obras desses autores.

As onze espécies com maior IR foram: Porophyllum ruderale (Asteraceae); Maytenus ilicifolia (Celastraceae) $(\mathrm{IR}=2,0)$; Croton urucurana (Euphorbiaceae), Cymbopogon citratus (Poaceae) $(\mathrm{IR}=1,7)$; Cedrela fissilis (Meliaceae) (IR=1,6); Stryphnodendron adstringens (Fabaceae) $(I R=1,5)$; Moquiniastrum polymorphum (Asteraceae) (IR=1,4); Ananas ananassoides (Bromeliaceae); Baccharis crispa (Asteraceae); Pterodon emarginatus (Fabaceae); Stachytarpheta cayennensis (Urticaceae) $(\mathrm{IR}=1,2)$.

Muitas das espécies de plantas encontradas neste trabalho são comumente citadas como tendo grande importância cultural como plantas medicinais no centro-oeste do Brasil (PEREIRA et al., 2009, 2012; CARNEIRO e dos SANTOS, 2013, 2014; BRATTI, et al., 2013; FONSECA et al., 2015).

No geral, espécies nativas demonstraram maiores valores de IR (média: 0,5; DP: 0,4) do que espécies cultivadas (média: 0,4; DP: 0,4), sendo essas diferenças estatisticamente significativas $(H=5,6 ; p<0,05)$. Além disso, são utilizadas mais plantas nativas (175 espécies) do que as cultivadas (30 spp.) (X2 =66,7; $\mathrm{p}<0,05$ ), indicando a importância das plantas nativas nos sistemas medicinais tradicionais entre as comunidades guarani e kaiowá. Árvores (64), arbustos e subarbustos (65) e plantas de hábito herbáceo (53) foram mais numerosas que as lianas (23) em um nível estatisticamente significativo ( $\chi 2=24,2 ; p<0,05)$. 


\section{O Reino vegetal e as plantas na ótica dos guarani e kaiowá}

Não existe categoria guarani e kaiowá para expressar ou se aproximar da ideia de Reino vegetal ou das plantas, como existe no pensamento não indígena. Existem categorias que expressam redes classificatórias conforme o interesse na produção da pessoa e de seu ser social pleno, nas quais o vegetal é visto como intermediador da relação com os guardiões (teko jára) que compõem os diversos lugares do tekoha (aldeia, território).

As plantas são consideradas seres que possuem almas e o estado aparente do vegetal é apenas uma miragem limitada dos humanos de enxergar a dimensão imcompleta dos ecossistemas, onde o mundo físico é apenas uma parte da totalidade da existência. O mundo "natural", entendido pelos povos indígenas guarani e kaiowá, é repleto de diferentes plantas e animais conforme a presença de seus guardiões que cuidam e proliferam cada espécie numa dinâmica de movimento.

De acordo com os guarani e kaiowá, cada organismo no mundo, incluindo as plantas de todas as diversas espécies, obtém um tipo de matriz ou ancestral que se denomina como ypy, os quais estão localizados nos patamares celestes (ára). Cada lugar no mundo atmosférico (ára resakã) está cheio desses mundos/aldeias invisíveis de diferentes ypy e uma parte bastante reduzida repousa na terra ( $y p y$ rupa), se ela estiver limpa (ausente) de todas as impurezas dos malefícios humanos (teko vai) e das substâncias que não atuam na manutenção do equilíbrio do lugar. Na morada do $y p y$ estão guardadas as maiores diversidades biológicas, inclusive as espécies que não conhecemos no mundo terreno em seu estado físico e por isso são consideradas seres mitológicos, como os guaruje (grandes morcegos originais), os ka'iu'y (macaco gente que usa arco e flecha) e o ñandukaru (ema original).

Os guardiões de potência maior, como o Chiru (dono do milho, das almas, das sabedorias, das águas), povoam os patamares de dimensões mais amplas, estabelecendo-se em fluxo e em movimento na busca do encontro com o Ñanderuvusu (divindade suprema estabelecido no sol nascente). Na passagem de diferentes Chiru pelo tekoha, há influência no clima e no microclima local. Além disso, são semeadas, neste movimento, diversas variedades de plantas que são utilizados como alimentos e remédios, com o objetivo de estimular a metamorfose dos corpos equilibrados, denominados ñande rete resakã (corpo transparente).

Assim, diferentes espécies de plantas existentes em determinado lugar da biodiversidade planetária, classificada como bioma pela ciência ocidental, na ótica guarani e kaiowá, são produtos ou o resultado da passagem de um tipo de guardião em um determinado local, elevando o grau de equilíbrio, de maneira sucessiva, para que outras plantas mais sensíveis (que ainda estão nos patamares inferiores) possam repousar de maneira lenta e gradativa como forma de embelezar a terra (ombojegua $y v y$ ) formando, assim, os caminhos (tape) dos guardiões. Por isso, na ótica indígena, o planeta Terrra é uma parte dos caminhos visíveis dos guardiões, estimulando a funcionalidade dos diferentes caminhos de passagens, visto como um conjunto de sistemas interconectados. 
Neste contexto, as plantas são seres intermediadores da viagem dos guardiões e a sua estratégia de proliferação (reprodução) é a dimensão do habitat, ou seja, o tekoha (aldeia, território) e também é o caminho de um determinado tipo de guardião, mantendo as espécies vivas e resistentes em seus lugares. O ato de pousar múltiplos guardiões em determinado lugar modela a paisagem do mundo vegetal, animal e de todo o conjunto abiótico, como o solo, as rochas e o próprio clima, caracterizando o tipo especifico de bioma formado pelo conjunto de microssistemas interconectados. Desta forma, se estabelece, nesse lugar e de forma coesa, o processo de movimento dos sistemas entre si, conhecido na língua guarani como teko joja (jeito harmônico e coeso de ser e de estar). Assim, a existência da paisagem natural, com seus sistemas vivos, depende da presença dos guardiões dos lugares e a ausência destes pode acarretar o desequilíbrio e a diminuição da biodiversidade local.

A categoria classificatória dos guarani e kaiowá sobre as plantas se dá no conjunto de interligação de y (água), yvy (terra), yvyra (árvores), yvytu (vento) e yvága ou ára (céu). Percebe-se que etimologicamente a palavra y (água) está em todos os outros componentes, porque, na visão indígena, da água primordial se originam todos os componentes que estruturam a vida e o mundo atual que conhecemos. Esta substância primeira é conhecida como jasuka (substancia açucarada e primordial da qual é formado o universo) e é considerada como responsável pela formação dos componentes da vida em sua plenitude, apresentando-se para os indígenas como água. Os guardiões que cuidam das águas denominam-se Chiru Yryvera ${ }^{10}$ (o ser de brilho reluzente da água) e residem na região denominada marány rupa (região sudoeste).

A composição da palavra Yvy+ra forma a palavra yvyra (árvore), de forma que, nesta junção, estão embutidos dois pensamentos $y v y$ (terra) e jyva (braço) e, assim, no yvyra se expressa a ideia de "braço da terra", através da qual, os guarani e kaiowá se relacionam com os guardiões, absorvendo, através da alimentação e da absorção das plantas medicinais, as forças dos guardiões acumuladas na terra. Por isso, a terra é vista como o lugar onde se acumulam as forças dos guardiões e as plantas, como as árvores, são intermédios ou vias por onde se acessarão as energias dos guardiões. Isto diante do objetivo de produzir ou metamorfosear o corpo guarani e kaiowá na sua plenitude, ou seja no teko araguyje.

Esta é apenas uma pequena discussão sobre a ótica dos povos indígenas guarani e kaiowá sobre a importância do Reinos vegetal e das plantas, a partir da sua cultura, apontando as lógicas e classificações que orientam o relacionamento desses seres vivos com a imensidão de seres estimuladores de energias do ecossistema, denominado Chiru (guardiões) ou teko jára (donos dos seres). Os saberes tradicionais aqui colocados são apenas um olhar inicial, sendo necessário ampliar este debate para trazer à tona os diversos saberes tradicionais específicos que

\footnotetext{
${ }^{10}$ Segundo relatos de $\tilde{N} a n d e s y$ Dona Amélia e Ñanderu Atanásio Teixeira. 
compõem o grande território guarani e kaiowá no cone-sul do estado de Mato Grosso do Sul/Brasil.

\section{Conclusão}

Do ponto de vista etnobiológico, e considerando as limitações deste estudo, entendemos que a IR pode ser considerada como um critério importante na seleção de espécies de plantas para estudos mais detalhados sobre aspectos ecológicos - como os que dizem respeito à conservação e à restauração da biodiversidade local - e antropológicos como as relações e ações políticas e espaciais de povos com seu território.

Nossa análise demonstrou que há um número expressivo de espécies de plantas medicinais conhecidas nas culturas guarani e kaiowá e que há necessidade de estudos etnobotânicos adicionais sobre as várias espécies que são de importância fundamental para a proteção desses povos e para a manutenção dos seus modos de vida, baseados no bem viver e no respeito incondicional a todos os seres vivos e à natureza. Por outro lado, nossas reflexões também apontam para a necessidade de um exame detalhado dos processos políticos e sociais que vêm atuando de forma intensa e têm tido como resultado a dizimação do restante da biodiversidade local dos territórios indígenas de todo o país e, em especial, o território guarani e kaiowá.

Desta forma, este estudo demonstrou a importância etnobotânica e etnoecológica de pesquisas baseadas em fontes secundárias. Um fato que consideramos relevante é que a grande maioria das plantas examinadas aqui são plantas nativas do território guarani e kaiowá que possuem grande importância biológica e cultural para esses povos. Desta forma, sugerimos que estas espécies sejam consideradas como prioritárias em estratégias de preservação, conservação e/ou restauração ambiental.

As análises aqui apresentadas foram baseadas em uma série de estudos realizados usando distintas metodologias e cobrindo uma pequena área geográfica. Territórios guarani e kaiowá mais ao noroeste do estado do Mato Grosso do Sul ainda não foram amostrados. Desta forma, sugerimos que nessa região trabalhos etnobotânicos sejam desenvolvidos, já que o domínio fitogeográfico dessa área é distinto do das áreas até aqui amostradas.

Por fim, pontuamos que na construção, execução, apresentação dos resultados e retorno às comunidades neste trabalho, nos somamos aos estudos pensados e construídos no âmbito da Etnobiologia da Política e da Ação, em que se busca reconhecer, refletir e interagir diante dos processos históricos, políticos e sociais, nos quais os povos, que são os principais atores na construção dessa ciência, estão inseridos. Almejamos, assim, construir uma Etnobiologia focada no reconhecimento e apoio às lutas dos povos na retomada de seus territórios ancestrais.

Assim, finalizamos este trabalho com as palavras de Ailton Krenak: "É importante viver a experiência da nossa própria circulação pelo mundo, não como uma metáfora, mas como fricção, poder contar uns com os outros" (KRENAK, 2019, p. 13). 
Espaço Ameríndio

\section{Referências bibliográficas}

ALBERT, Bruce. O ouro canibal e a queda do céu. In: ALBERT, Bruce; RAMOS, Alcida Rita (Org.). Pacificando o branco: cosmologias do contato no norte amazônico. São Paulo: Ed. Unesp, 2002.

ALBUQUERQUE, Ulysses Paulino. Introdução à Etnobotânica. $2^{\mathrm{a}}$ ed. Rio de Janeiro: Interciência, 2005.

ALBUQUERQUE, Ulysses Paulino et al. Métodos e técnicas para coleta de dados Etnobiológicos. In: ALBUQUERQUE, Ulysses Paulino et al. Introdução a Etnobotânica. Recife: Nuppea, 2010.

ALBUQUERQUE, Ulysses Paulino; MEDEIROS, Patrícia Muniz. Systematic reviews and meta-analysis applied to ethnobiological research. Ethnobiology and Conservation, v. 1, 2012.

AMOROZO, Maria Christina de Mello. Uso e diversidade de plantas medicinais em Santo Antônio do Leverger, MT, Brasil. Acta botanica brasílica, v. 16, n. 2, p. 189-203, 2002.

BENITES, Eliel. Oguata Pyahu (Uma Nova Caminhada) no processo de desconstrução e construção da educação escolar indígena da aldeia Te'ýikue. 2014. 165f. Dissertação (Mestrado em Educação). Universidade Católica Dom Bosco - UCDB, Campo Grande, MS, 2014.

BENITES, Eliel; PEREIRA, Valdivina Zefa; SANGALLI, Andréia. O estudo das espécies arbóreas e o significado das mesmas para a cosmologia guarani e Kaiowa da aldeia Te'yikue município de Caarapó-MS. In: SANGALLI, Andréia; LADEIA, Elâine da Silva; BENITES, Eliel; PEREIRA, Valdivina Zefa. (Orgs.). Tekoha Ka'aguy: Diálogos entre saberes guarani e kaiowá e o ensino de Ciências da Natureza. Jundiaí: Paco Editorial, 2017, v. 1, p. 83-106.

BENITES, Iracy Lima et al. As plantas medicinais e o ensino da botânica na aldeia Amambai. In: SANGALLI, Andréia; LADEIA, Elâine da Silva; BENITES, Eliel; PEREIRA, Valdivina Zefa. (Orgs.). Tekoha Ka'aguy: Diálogos entre saberes guarani e kaiowá e o ensino de Ciências da Natureza. Jundiaí: Paco Editorial, 2017, v. 1, p. 5581 .

BENITES, Eliel. Tekoha Ñeropu'ã: aldeia que se levanta. Presidente Prudente: Revista Nera: Dossiê, 2020.

BENNETT, Bradley; PRANCE, Ghillean. Introduced plants in the indigenous pharmacopoeia of Northern South America. Economic Botany, v. 54, p. 90-102, 2000.

BRAND, Antônio Jacó. Biodiversidade, sócio-diversidade e desenvolvimento: os guarani e kaiowá no Estado de Mato Grosso do Sul. Fragmentação florestal e alternativas de desenvolvimento rural na região Centro-Oeste. Campo Grande: UCDB, v.7 p. 175-204, 2003. 
BRATTI, C. et al. Levantamento de plantas medicinais nativas da Fazenda Azulão em Dourados-MS. Revista Brasileira de Plantas Medicinais, v. 15, n. 4, p. 675-683, 2013.

BUENO, Norlene Regina et al . Medicinal plants used by the guarani and kaiowáindigenous populations in the Caarapó Reserve, Mato Grosso do Sul, Brazil. Acta Bot. Bras. São Paulo: v. 19, n. 1, p. 39-44, 2005.

CARNEIRO, Marcos Rodrigo Beltrão; dos SANTOS, Mirley Luciene. Os recursos vegetais medicinais utilizados pela população da região Centro Oeste do Brasil: uma compilação de espécies ou Checklist de Fanerógamas. Fronteiras: Journal of Social, Technological and Environmental Science, v. 2, n. 1, p. 28-42, 2013.

CARNEIRO, Marcos Rodrigo Beltrão; dos SANTOS, Mirley Luciene. Importância relativa de espécies com potencial uso medicinal na flora do Centro Oeste do Brasil. Fronteiras: Journal of Social, Technological and Environmental Science, v. 3, n. 2, p. 145$163,2014$.

CAVALCANTE, Thiago Leandro Vieira. Demarcação de terras indígenas guarani e kaiowá em Mato Grosso do Sul: histórico, desafios e perspectivas. Fronteiras, v. 16, n. 28, p. 48-69, 2014.

CHAMORRO, Graciela. Terra Madura Yvy Araguyje: fundamento da palavra guarani. Dourados: UFGD, 2009.

CHAMORRO, Graciela. História kaiowá. São Bernardo do Campo: Nhanduti, 2014

CHAMORRO, Graciela; COMBÈS, Isabelle. Povos indígenas em Mato Grosso do sul: História, culturas e transformações sociais. Revista Caminhos: Revista de Ciências da Religião, v. 17, n. 1, p. 397-403, 2019.

COLMAN, Rosa Sebastiana; PEREIRA, Levi Marques. Territorialidade e Sustentabilidade: Desafios para as comunidades guarani e kaiowá em Mato Grosso do Sul, Brasil. Revista Nera, n. 52, p. 63-89, 2020.

CUNNINGHAM, Anthony. Etnobotánica aplicada. Pueblos, uso de plantas silvestres y conservación. Montevideo: Ed. Nordan-Comunidad, 2001.

DIEGUES, Antonio Carlos. Os saberes tradicionais e a biodiversidade no Brasil. São Paulo: USP, 2000.

DI STASi, Luiz Claúdio, et al. Medicinal plants popularly used in the Brazilian Tropical Atlantic Forest. Fitoterapia, v. 73, p. 69-91, 2002.

FONSECA, Maira Christina Marques, et al. Potencial de óleos essenciais de plantas medicinais no controle de fitopatógenos. Revista Brasileira de Plantas Medicinais, v. 17, n. 1, p. 45-50, 2015. 
Espaço Ameríndio

GALVÃO, Eduardo. Diários de Campo de Eduardo Galvão: entre os Tenetehara, Kaioá e índios do Xingu. Rio de Janeiro: UFRJ, Museu do Índio, Funai, 1996.

GAZZANEO, Luiz Rodrigo Saldanha et al. Knowledge and use of medicinal plants by local specialists in an region of Atlantic Forest in the state of Pernambuco (Northeastern Brazil). Journal of Ethnobiology and Ethnomedicine, v. 1, n. 9, 2005.

HANAZAKI, Nathalia, et al. Diversity of plant uses in two Caic, ara communities from the Atlantic Forest coast, Brazil. Biodiversity and Conservation, v. 9, p. 597-615, 2000 .

IBGE - Instituto Brasileiro de Geografia e Estatística. Censo Demográfico 2010. Brasil.

(https://censo2010.ibge.gov.br/noticiascenso?busca $=1 \& \mathrm{id}=3 \&$ idnoticia $=2194 \& \mathrm{t}=$ censo2010-poblacao-indigena-896-9-mil-tem-305-etnias-fala-274\&view=noticia), 2013.

KING, Steven R.; TEMPESTA, Michael S. From shaman to human clinical trials: The role of industry in ethnobotany, conservation, and community reciprocity. Ethnobotany and the search for new drugs, 1994.

KOPENAWA, Davi; ALBERT, Bruce. A queda do céu. Palavras de um xamã Yanomami. São Paulo: Companhia das Letras, 2015.

KRENAK, Ailton. Paisagens, territórios e pressão colonial. Espaço Ameríndio, v. 9, n. 3, p. 327, 2015.

KRENAK, Ailton. Ecologia Política. Ethnoscientia, v. 3, n. 2, 2018.

KRENAK, Ailton. Ideias para adiar o fim do mundo. Companhia das Letras, 2019.

JOÃO, Ifigeninha Hirto. As plantas e os conhecimentos tradicionais no tratamento de doenças na comunidade indígena da Aldeia Panambi-Douradina-MS. In: SANGALLI, Andréia; LADEIA, Elâine da Silva; BENITES, Eliel; PEREIRA, Valdivina Zefa. (Orgs.). Tekoha Ka'aguy: Diálogos entre saberes guarani e kaiowá e o ensino de Ciências da Natureza. Jundiaí: Paco Editorial, 2017, v. 1, p. 55-81.

LATOUR, Bruno. Jamais fomos modernos ensaio de antropologia simétrica. Editora 34, 1994.

LOPES, Jussara Marques; SANGALLI Andréia; PEREIRA, GONÇALVES, Joelson. O conhecimento tradicional e o uso de plantas medicinais por mulheres indígenas da aldeia Jaguapiru. In: SANGALLI, Andréia; LADEIA, Elâine da Silva; BENITES, Eliel; PEREIRA, Valdivina Zefa. (Orgs.). Tekoha Ka'aguy: Diálogos entre saberes guarani e kaiowá e o ensino de Ciências da Natureza. Jundiaí: Paco Editorial, 2017, v. 1, p. 4153 .

MELIÁ, Bartomeu; GRÜNBERG, Georg; GRÜNBERG, Friedl. Los Paĩ-Tavyterã: etnografía guaraní del Paraguay contemporáneo. Centro de Estudios Antropológicos, Universidad Católica Nuestra Señora de la Asunción, 1976. 
MELO, Paula Maria Correa de Oliveira et al. Coleções etnobotânicas no Brasil frente à estratégia global para a conservação de plantas. Boletim do Museu Paraense Emílio Goeldi. Ciências Humanas, v. 14, n. 2, p. 665-676, 2019.

MILLION, Janae Lyon. Estudo etnobotânico na comunidade de Taquara: a luta pelo uso de plantas nativas pelo povo kaiowá, MS, Brasil. 2017. 147 f. Dissertação (Mestrado em Botânica) - (PPG - Bot/UnB), Brasília, DF, 2017.

MONDARDO, Marcos Leandro. No território do agronegócio à luta pelo retorno ao tekoha: o conflito territorial envolvendo guarani-kaiowá e fazendeiros em Mato Grosso do Sul. Revista GeoNorte, v. 7, p. 767-781, 2013.

MONDARDO, Marcos Leandro. O Movimento guarani e kaiowá pela reapropriação social da natureza e as retomadas de Tekoha. Revista Nera, n. 52, p. 133-150, 2020.

MOTA, Juliana Grasiéli Bueno. Territórios de resistência e práticas descoloniais: estratégias de luta guarani e kaiowá pelo Tekoha-Mato Grosso do Sul/Brasil. Campo Território: Revista de Geografia Agrária, v. 10, n. 20, 2015.

MOTA, Juliana Grasiéli Bueno; GOETTERT, Jones Dari. Geografias indígenas no/do Mato Grosso do Sul. Revista Nera, n. 52, p. 7-18, 2020.

PEREIRA, Levi Marques. Mobilidade e processos de territorialização entre os kaiowá atuais. Revista História em Reflexão, n. 1, v. 1, 2007.

PEREIRA, Levi Marques. Demarcação de terras kaoiwa e guarani em MS: ocupação tradicional, reordenamentos organizacionais e gestão territorial. Tellus, n. 18, p. 115137, 2014.

PEREIRA, Levi Marques. Os kaiowá em Mato Grosso do Sul: módulos organizacionais e humanização do espaço habitado. Ed. UFGD. Dourados, MS, 2016.

PEREIRA, Levi Marques, MOTA, Juliana Grasiéli Bueno. Movimento étnico-socio territorial guarani e kaiowá em Mato Grosso do Sul: atuação do Estado, impasses e dilemas para demarcação de Terras Indígenas. Boletim Dataluta: Oktober, 2012.

PEREIRA, Zefa Valdivina et al. Medicinal plants used by Ponta Porã community, Mato Grosso do Sul state. Acta Scientiarum. Biological Sciences, v. 31, n. 3, p. $293-$ 299, 2009.

PEREIRA, Zefa Valdivina et al. Usos múltiplos de espécies nativas do bioma Cerrado no Assentamento Lagoa Grande, Dourados, Mato Grosso do Sul. Revista Brasileira de Agroecologia, v. 7, n. 2, p. 126-136, 2012.

POSEY, Darrell Addison. Etnobiologia: teoria e prática. Suma etnológica brasileira, v. 1, p. 15-25, 1987.

PRADO, Amanda et al. Etnobotânica como subsídio à gestão socioambiental de uma unidade de conservação de uso sustentável. Rodriguésia, v. 70, n. 1, 2019. 
Espaço Ameríndio

REGO, Flávio Luís Hilário; BRAND, Antonio Jacó; COSTA, Reginaldo Brito da. Recursos genéticos, biodiversidad, conocimiento tradicional kaiowá y guarani y el desarrollo local. Campo Grande: Interações, v. 11, n. 1, p. 55-69, 2010.

RODRIGUES, Eliana. Plants and animals utilized as medicines in the Jau National Park (JNP), Brazilian Amazon. Phytotherapy Research, v. 20, p. 378-391, 2006.

RODRÍGUEZ-SILVA, Cristhian Neil et al. Agracejo: Muchas especies, escasa información etnobotánica $\mathbf{y}$ etnofarmacológica. Ethnobotany Research and Applications, v. 19, p. 1-12, 2020.

SALLES, Ayr Trevisanelli; VALÉRIO FILHO, Mário; FLORENZANO, GALLOTTI, Teresa. Monitoramento da cobertura vegetal e do uso do solo da reserva indígena Caarapó-MS, através de técnicas de sensoriamento remoto e geoprocessamento. Multitemas, n. 12, 2016.

SANTOS, Antônio Bispo dos. Colonização, quilombos: modos e significações. Brasília: Instituto de Inclusão no Ensino Superior e na Pesquisa, 2015.

SANTOS, Deyvison Luz et al. Saberes tradicionais sobre plantas medicinais na conservação da biodiversidade amazônica. Ciências Em Foco, v. 12, n. 1, 2019.

SCHEFFER, Marianne Christina; MING, Lin Chau; ARAÚJO, AJ de. Conservação de recursos genéticos de plantas medicinais. Recursos genéticos e melhoramento de plantas para o Nordeste brasileiro, v. 1, p. 1-25, 1999.

SOKAL, Robert; RHOLF, James. Biometry, New York: 3rd ed Freeman and Company, 1995.

TOMCHINSKY, Bernardo, et al. Publicações científicas das etnociências-caminhos passados e futuros. Ethnoscientia, 2019, 4.1.

VIETTA, Katya. Relatório final da Perícia realizada na Área Indígena de Perícia realizada a pedido do Sr. Juiz Federal da I Vara de Seção Judiciária de Mato Grosso do Sul, 1998.

OMS (WHO). International Statistical Classification of Diseases and Related Health Problems, 10th Revision. 2006. Disponível em http://www.who.int (acesso em 15 de maio de 2020). 